Research Article

\title{
Simulation Research on the Load Transfer Mechanism of Anchoring System in Soft and Hard Composite Rock Strata under Tensile Loading Conditions
}

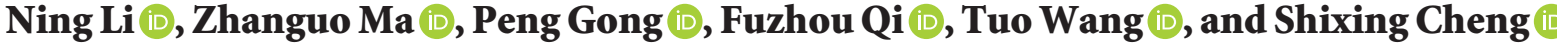 \\ State Key Laboratory for Geomechanics and Deep Underground Engineering, School of Mechanics and Civil Engineering, \\ China University of Mining \& Technology, Xuzhou 221116, China \\ Correspondence should be addressed to Zhanguo Ma; 1044@cumt.edu.cn
}

Received 27 May 2019; Revised 9 May 2020; Accepted 26 May 2020; Published 17 June 2020

Academic Editor: Erdin Ibraim

Copyright (C) 2020 Ning Li et al. This is an open access article distributed under the Creative Commons Attribution License, which permits unrestricted use, distribution, and reproduction in any medium, provided the original work is properly cited.

Soft and hard composite rock strata are frequently encountered in transportation, geotechnical, and underground engineering. However, most of the current support is designed for homogeneous rock masses, which ignores the different anchoring effect in soft and hard composite rock strata. A numerical study is presented in this paper on the pull-out behavior of fully grouted rock bolts in soft and hard composite rock strata. The nonlinear bond-slip relationship of bolt-grout interface that is anchored in soft rock and hard rock is obtained from laboratory test, respectively. Then, the nonlinear bond-slip relationship is put into the numerical model. The numerical result shows a close match with the experiment tests and the proposed model. Lithological sequence, layer thickness ratio, and layer numbers are taken into consideration in numerical simulation models. Under the same layer number, the shallower-soft and deeper-hard composite rock strata (SHCRS) have a higher bearing capacity and deformation resistance than the shallower-hard and deeper-soft composite rock strata (HSCRS). As the soft-to-hard thickness ratio in SHCRS increases, the initial stiffness of the load-displacement curve and peak load decreases continuously. The load-displacement curve shows the same initial stiffness for different hard to soft thickness ratios in HSCRS. As the hard to soft thickness ratio increases, the load peak and the displacement at the peak load increase. Therefore, the closer the hard rock is to the loading end, the greater the initial stiffness of the load-displacement curve is. The greater the hard rock thickness, the larger the peak load. Under the same anchor length, the peak load and the displacement at the peak load decrease with the increase of layer numbers, but the reduction magnitude decreases. This paper leads to a better understanding of the load transfer mechanism for the anchoring system in soft and hard composite strata and provides a reference for scientific support design and evaluation method.

\section{Introduction}

In the past few decades, rock bolts and cable bolts support technology have become the main means to strengthen surrounding rock strength in the fields of construction, water conservancy, underground space, and so on, with the advantages of low cost, high reliability, and high carrying capacity $[1,2]$. The rock bolts anchoring system is a composite material system consisting of three materials and two interfaces. Some scholars [3-6] found that the external force is transferred to the surrounding rock masses through the interfacial bonding force, mechanical interlock force, and friction force among the bolt, anchorage agent, and surrounding rock masses under pull-out test, so as to achieve the anchorage equilibrium and reinforce rock masses. Xing et al. [7] quantitatively analyzed the mechanical interlock force, friction force, and interfacial bonding force between deformed bar, plain bar, plain Al-alloy, and concrete. Many scholars have devoted to the study on the influencing factors of bearing capacity of rock bolts or cable bolts. Liu and Kaiser [8] established the bond strength model (BSM) based on the thick wall cylinder theory and described in detail the influencing factors of bond strength as follows: the mechanical properties of both rock and grout as well as the geometry of the borehole and the rock bolt. It confirmed that grouted cables have the more bond strength in hard rock 
than in soft rock. Hyett et al. [9] investigated that the anchoring capacity of the cable bolts is mainly affected by the cement properties, the embedment length, and the radial confinement acting on the outer surface of the cement annulus by many indoor and field experiments. Later, Hyett et al. $[10,11]$ conducted a series of laboratory pull-out tests in a modified Hoek cell. The results showed that the higher the radial confining pressure, the higher the peak strength, but the relationship is not linear. Moosavi et al. [12-14] developed an analytical model based on linear dilation assumption and conducted a series of parametric studies using both plain and modified cable bolts. The results showed that the bond failure mechanism for cable bolts is a frictional dilatational process controlled by the helical surface morphology of the cable. The higher axial load and radial dilatation are generated in the modified cables than in conventional cables depending on the degree of confinement provided by the rock masses. Kilic et al. [15] conducted approximately 80 rock bolts pull-out tests in basalt blocks and obtained the influence law to the pull-out load capacity of shear strength, uniaxial compressive strength and curing time of the grouting material, bolt length, bolt diameter, and bonding area. Thenevin et al. [16] confirmed the influence of the confining pressure and the embedment length on the pull-out response through the laboratory pull-out tests with the different types of rock bolts and cable bolts. Chen et al. [17] studied the effects of the radius and boundary conditions (the unconfined condition and the confined condition) of cylindrical specimens on the bond properties of cable bolts through laboratory pull-out tests. It should be noted that these research methods are focused on the influencing factors of bearing capacity of rock bolts or cable bolts which are anchored in homogeneous rock masses, and the soft and hard composite rock strata are not involved.

However, the soft and hard composite rock masses are very common in slopes, tunnels, mining projects, and so on, especially in sedimentary strata. Figure 1 shows the soft and hard composite rock strata in underground engineering of coal mining, the thickness of which varies from 0.3 to $1.0 \mathrm{~m}$ and an exposed rock bolt when the roadway is repaired. It can be seen that there is an obvious soft-hard interface; the bond segment in soft rock has been partially debonding, and the anchorage agent has fallen off. It is very common that rock bolts or cable bolts penetrate two or more rock strata in the soft and hard composite rock strata, especially in the slanted soft and hard composite rock strata (as shown in Figure 2). The different bearing capacity of each rock bolt embedded in soft and hard composite rock strata leads to the differences in the supporting strength in the roadway section, which is likely to cause the local failure of the support system and affect the overall stability of roadway.

Some earlier scholars [18-20] had pointed out that the soft and hard layered rock masses had obvious inhomogeneity and layering characteristics due to the difference of mechanical properties of lithology (strength, elastic modulus, Poisson's ratio, etc.). Wang et al. [21] analyzed the distribution of interfacial shear stress in the tension of glass fiber reinforced polymer bolt by numerical analysis. The results showed that the interfacial shear stress was distributed more evenly with less concentration with less elastic modulus of rock masses. Michael Salcher et al. [22] conducted 181 field pull tests of rock bolts and cable bolts in Sydney Metro Northwest tunneling and analyzed the influence rules of lithology, bolt type, grouting agent, bolt bar material, and borehole diameter on the anchoring effect. The results showed that lithology had a great influence on the bonding strength.

Previous studies on the influencing factors of anchorage in homogeneous rock have obtained many beneficial results, but the axial force, shear stress distributions along the rock bolt, and the load-displacement response of the anchoring system in soft and hard composite rock strata need further study. Physical tests in situ or in laboratory are common methods to evaluate the mechanical properties of the rock bolt system. However, it is difficult to capture the evolution of axial force and shear stress distributions. Therefore, a numerical analytical method based on the bond-slip relationship is proposed to study the influence of lithological sequences, layer-thickness ratio, and layer numbers on the load transfer mechanism in soft and hard composite strata.

\section{Bond Slip Relationship of Bond Interface}

The anchoring agent bonds the rock bolts to the surrounding rock. The bond-slip relationship is essential to the study of the macromechanical properties of anchorage body. Some scholars have done a lot of research work on the axial force and shear stress distribution characteristics of the anchoring system, mostly based on the experimental method. Teymen et al. [23] measured the strain values of steel bars and concrete interface by laying strain gauges on the surface of steel bars during the loading process and obtained the $\tau$-s curve after integration. Farmer et al. [24] proposed the shear stress on the bolt-resin interface which was exponentially attenuated with the increase of depth along the rock bolt before the slipping or debonding occurs. Aydan et al. [25] deduced an analytical solution to study the load transfer of rock bolts. Later, Aydan et al. [26] proposed a finite element for grouted rock bolts to illustrate the interaction phenomena between rock bolts and rock masses. Li and Stillborg [27] developed an analytical model to study the load distribution of rock bolts, based on the shear stress distribution along the rock bolt. It can describe the decoupling process of anchoring interface successfully. Benmokrane et al. [28] proposed a classical trilinear bond-slip model as depicted in Figure 3(a). Ren et al. [29] obtained the analytical solutions of the axial force and shear stress distribution under elastic, elastoplastic, and plastic state based on the trilinear bondslip model and analyzed the load distribution and transfer mechanism of the anchorage section during the loading process. However, experiment tests show that the bond stress and the relative slip are nonlinearly related.

To obtain a better understanding of the interfacial mechanical behavior, it is essential to investigate the nonlinear constitutive relations. Dai et al. [30, 31] and Zhou et al. [32] conducted indoor experiments on the bonding properties of Fiber Reinforced Polymer (FRP) materials and obtained the nonlinear bond-slip relationship and control 


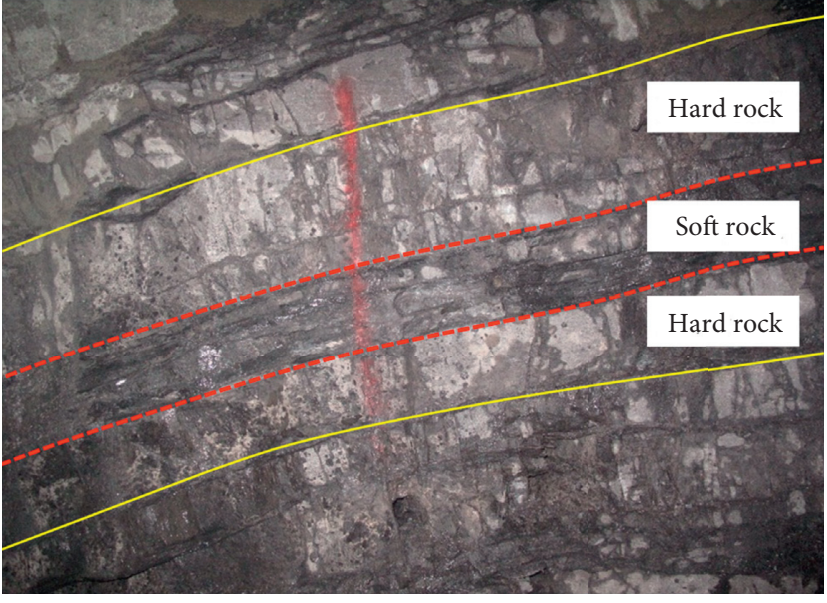

(a)

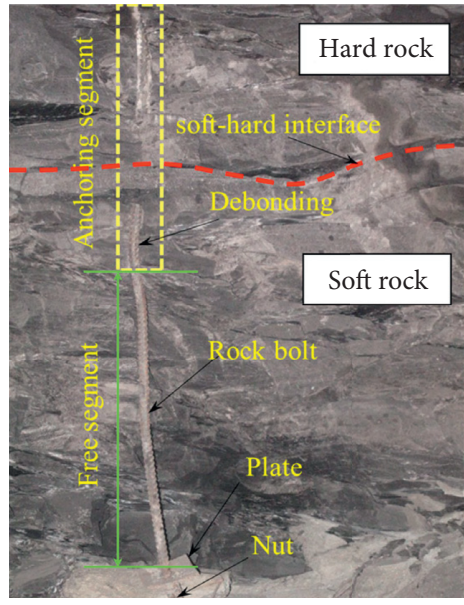

(b)

FIgURE 1: (a) Typical soft and hard composite rock strata in underground engineering and (b) an exposed rock bolt in situ.

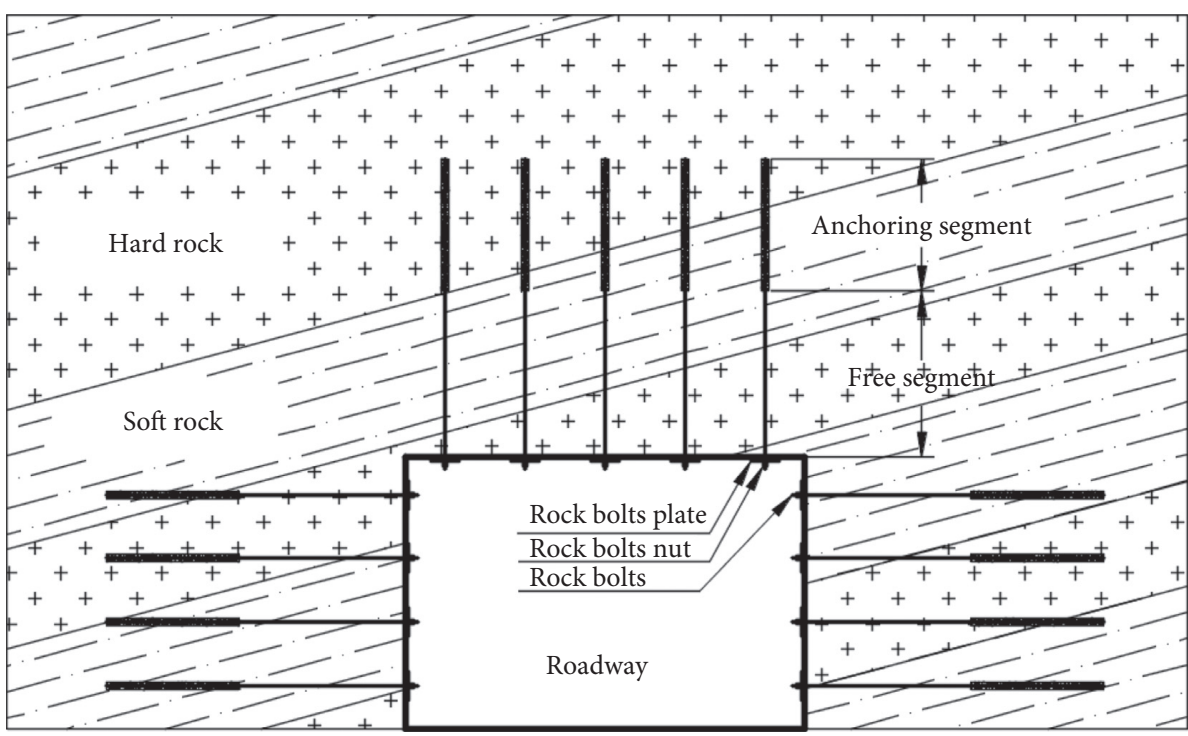

FIGURE 2: Schematic diagram of roadway support in the slanted soft and hard composite rock strata.

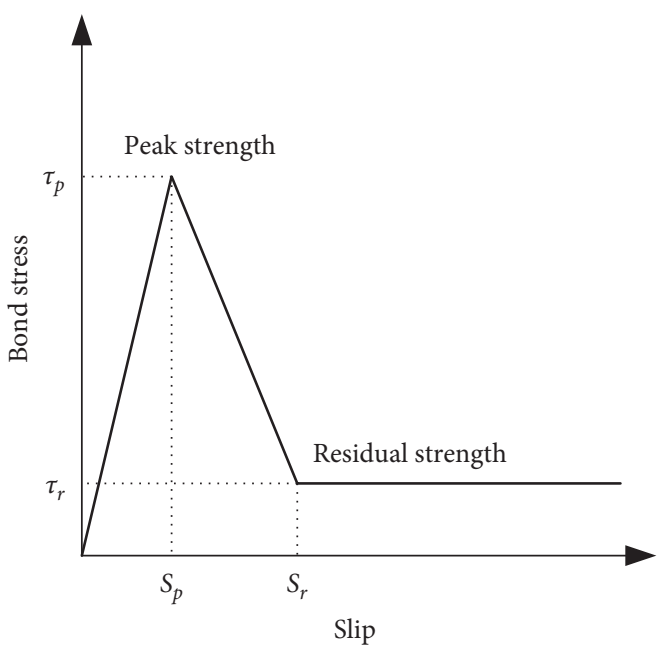

(a)

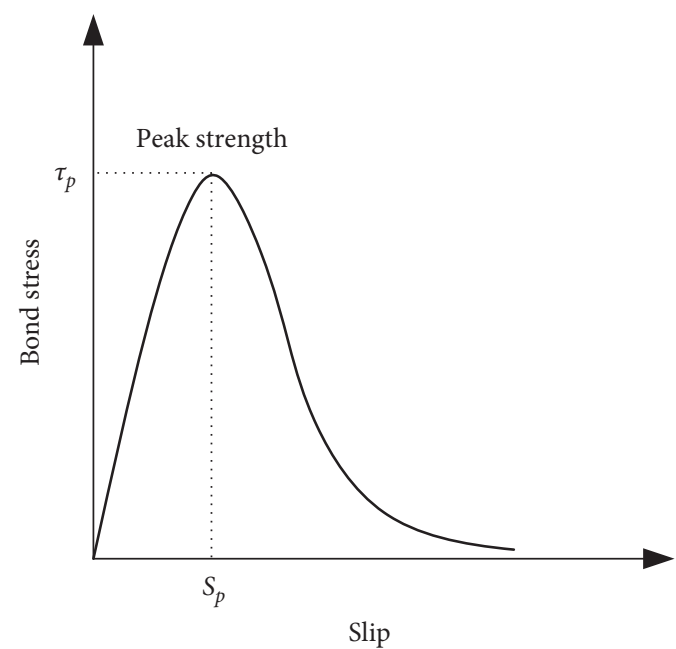

(b)

Figure 3: Evolution of the bond-slip model. (a) Trilinear model. (b) Nonlinear model. 
equation as depicted in Figure 3(b). Ma et al. [33] proposed a nonlinear bond-ship model for a fully grouted rock bolt based on the method used by Zhou et al. [32] and conducted short anchor pull-out tests in seamless steel tubes (anchor lengths of $36 \mathrm{~mm}$ and $75 \mathrm{~mm}$ ). The test results were in accordance with the nonlinear bond-slip relationship. Further, Martin et al. [34, 35] and Ma et al. [36] pointed out the bond-slip relationship is the constitutive law of blotgrout interface, which is independent on the embedment length. In other words, the bond interface has the same bond-slip relationship when subjected to the same conditions (such as the same installing procedure, rock bolt, grout, surrounding rock masses, and the same geological condition) under different anchor lengths.

The proposed analytical model requires the following four assumptions [29, 34, 37]: (a) the deformation of the surrounding rock is negligible; (b) the bond interface has the same bond-slip relationship under the same conditions; (c) failure occurs at the bolt-grout interface; (d) the rock bolt works at linear elastic state. When the bolt is subjected to the pull-out load $P$, the shear stress of the bond interface $\tau(x)$, the bolt strain at any position $\varepsilon(x)$, and the relative slip of bond interface $s(x)$, the rigid body displacement at the free end $s_{0}$ and the anchor length $L$ are schematically illustrated in Figure 4.

The stress distribution in an elementary length $\mathrm{d} x$ is taken for analysis. According to the mechanical equilibrium relationship, the following can be obtained:

$$
(\sigma(x)+\mathrm{d} \sigma(x)-\sigma(x)) \cdot A=\tau(x) \cdot U \cdot \mathrm{d} x,
$$

where $A$ is the cross-sectional area of rock bolt and $U$ is the circumference of the rock bolt rebar cross section.

Rewriting equation (1), we have

$$
\tau(x)=\frac{A}{U} \cdot \frac{\mathrm{d} \sigma(x)}{\mathrm{d} x},
$$

where $\sigma(x)$ is the axial tensile stress of rock bolt and $\tau(x)$ is the interfacial shear stress.

The deformation of the surrounding rock is assumed to be zero. Hence, the relative slip of bond interface $s(x)$ can be calculated as the sum of the rigid body displacement at the free end of rock bolt and the integration of the strains from the free end to the considered point $x$ :

$$
s(x)=s_{0}+\int_{0}^{x} \varepsilon(x) \mathrm{d} x .
$$

Rewriting equation (3), we have

$$
\varepsilon(x)=\frac{\mathrm{d} s(x)}{\mathrm{d} x} \text {. }
$$

Equation (4) also holds when $s_{0}$ is not 0.

The rock bolt is assumed to be in an elastic state; then,

$$
\sigma(x)=E \cdot \varepsilon(x)
$$

where $E$ is Young's modulus of rock bolt.

According to equations (2), (4), and (5),

$$
\tau(x)=\frac{\mathrm{EA}}{U} \cdot \frac{\mathrm{d} \varepsilon(x)}{\mathrm{d} x}=\frac{\mathrm{EA}}{U} \cdot s^{\prime \prime}(x) .
$$

Therefore, the distribution characteristics of the shear stress of the bond interface can be obtained if the distribution of the axial displacement $s(x)$ along the rock bolt is known.

Zhou et al. [32] proposed that there is a corresponding and unique distribution of the internal deformations and stresses at the bond interface for a certain pull load $P$ at the loaded end. The relative slip $s(x)$ of the bond interface is regular at different loading levels and can be represented by

$$
s(x)=\alpha \ln \left(1+e^{\left(x-x_{0}\right) / \beta}\right),
$$

where $\alpha, \beta$, and $x_{0}$ are the undetermined coefficients.

$$
\begin{aligned}
& \mathcal{E}(x)=s^{\prime}(x)=\frac{\alpha}{\beta} \cdot \frac{1}{\left(1+e^{\left(x_{0}-x\right) / \beta}\right)}, \\
& \tau(x)=\frac{\mathrm{EA}}{U} s^{\prime \prime}(x)=\frac{\mathrm{EA}}{U} \cdot \frac{\alpha}{\beta^{2}} \cdot \frac{e^{\left(x_{0}-x\right) / \beta}}{\left(1+e^{\left(x_{0}-x\right) / \beta}\right)^{2}}, \\
& P(x)=\operatorname{EA} \varepsilon(x)=\frac{\mathrm{EA} \alpha}{\beta} \cdot \frac{1}{\left(1+e^{\left(x_{0}-x\right) / \beta}\right)} .
\end{aligned}
$$

Rewriting equation (7), we have

$$
e^{\left(x-x_{0}\right) / \beta}=e^{s(x) / \alpha}-1 .
$$

Substituting equation (11) into equations (8)-(10) gives

$$
\begin{aligned}
& \mathcal{E}(s(x))=\frac{\alpha}{\beta} \cdot\left(1-e^{-s(x) / \alpha}\right), \\
& \tau(s(x))=\frac{\mathrm{EA}}{U} \cdot \frac{\alpha}{\beta^{2}} \cdot\left(e^{-(s(x) / \alpha)}-e^{-(2 s(x) / \alpha)}\right), \\
& P(s(x))=\frac{\mathrm{EA} \alpha}{\beta} \cdot\left(1-e^{-(s(x) / \alpha)}\right) .
\end{aligned}
$$

Equation (14) describes the load-displacement relationship of the loading end when $x=L$ ( $L$ is the anchoring length). The undetermined coefficients $\alpha$ and $\beta$ are obtained by data fitting from the pull-out test. Then, the nonlinear bond-slip relationship of the bond interface can be obtained by using equation (13).

Differentiation equation (14) with respect to $s(x)$ can be obtained as

$$
P_{\prime}(s(x))=\frac{\mathrm{EA}}{\beta} \cdot e^{-(s(x) / \alpha)} .
$$

When $s(x)=0$, equation (15) is

$$
P \prime(0)=\frac{E A}{\beta}=K_{0} .
$$

From equation (14), the maximum load can be obtained from 


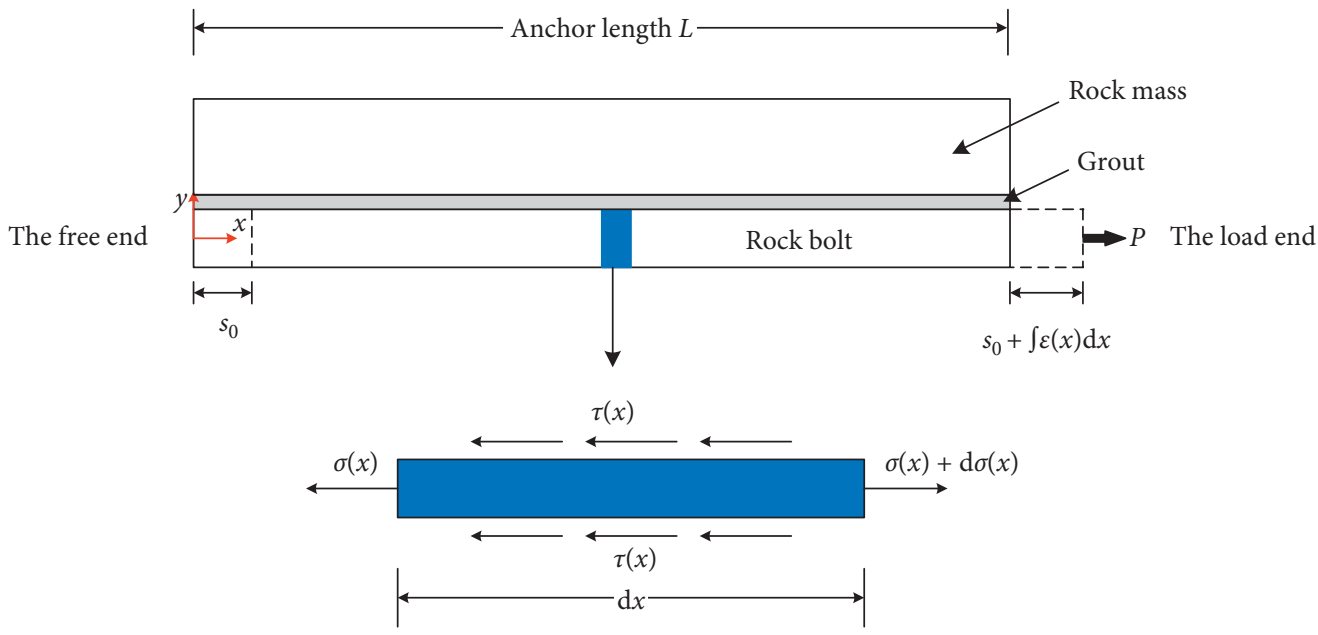

FIgURE 4: Calculation model of fully grouted bolt under tensile loading conditions.

$$
P_{\max }=\frac{\mathrm{EA} \alpha}{\beta} .
$$

Therefore, the coefficient $\alpha$ can be expressed by

$$
\alpha=\frac{P_{\max } \cdot \beta}{\mathrm{EA}}=\frac{P_{\max }}{K_{0}} .
$$

As illustrated in Figure 5(a), the coefficient $\alpha$ represents the slip at the turning point of the load-displacement curve and the coefficient $\beta$ dominates the initial tangential stiffness of the load-displacement curve [33].

\section{Numerical Model Construction}

3.1. PILE Structure Element in Flac3D. Flac3D is commonly used in mining and civil engineering for simulating soil, rock, and structural behavior. Cable and pile structure elements can simulate the anchorage characteristics very well in Flac3D, and the pile structure element gives the user a customizable cs_sctable to define the relationship between the maximum bond force and the shear displacement, which can better describe the postpeak softening characteristics of the bond interface [38].

Pile structural element interacts with the solid element (surrounding rock masses) via shear and normal coupling spring-slider system as seen in Figure 6. Springs represent the bond stiffness and slider represents the maximum bond force. This paper aims to study the shear behavior of the bond interface and does not take into account the normal behavior. The mechanical properties of the pile structural elements shear coupling spring are shown in Figure 7:

$$
\frac{F_{s}}{L}=k_{s} \cdot\left|u_{s}\right|
$$

where $F_{s}$ is the shear force in shear coupling spring, $k_{s}$ is coupling spring shear stiffness (in the simulation model: cs_sstiff), and $u_{s}$ is the relative displacement between structural elements and surrounding rock masses:

$$
\frac{F_{s}^{\max }}{L}=c_{s}+\sigma_{m} \cdot \tan \left(\phi_{s}\right) \cdot \text { perimeter }
$$

where $c_{s}$ is cohesive strength of the shear coupling spring (in the simulation model: cs_scoh), $\sigma_{m}$ is mean effective confining stress normal to the pile element, $\varphi_{s}$ is the friction angle of the shear coupling spring (in the simulation model: cs_sfric), and the perimeter is exposed perimeter of the pile element.

If the shear coupling spring friction angle is not considered, that is, cs_sfric $=0$, the maximum shear force per unit length of the structural element is only related to cs_scoh. Therefore, a function of the bond strength and relative displacement of the shear coupling spring can be expressed by cs_sctable, which provides a method for inputting an existing bond-slip function into the numerical simulation model.

Cs_scoh $(\mathrm{N} / \mathrm{m})$ represents the bond strength of the element length shear spring and can be expressed by the following formula:

$$
\mathrm{cs}_{\mathrm{scoh}}=\pi \cdot d \cdot \tau,
$$

where $d$ is rock bolt diameter, $m$, and $\tau$ is the shear stress along the rock bolt, $\mathrm{Pa}$.

Therefore, the mathematical relationship of the bondslip mode can be transferred into the relationship between the shear displacement and cs_scoh by equation (21). Then, the bond-slip relationship of soft rock and hard rock is put into the numerical simulation model by user-defined table cs_cstable for expressing the nonlinear characteristics of the bond interface [39].

3.2. Model Verification. In order to verify the accuracy of the present rock bolt model, the predictions using the numerical method are compared with the pull-out test conducted by Rong et al. [40] and Chen et al. [41]. Rong et al. applied a tensile load to a $1 \mathrm{~m}$ long and $32 \mathrm{~mm}$ diameter thread steel rock bolt encapsulated in concrete (hard rock). Chen et al. applied a $5 \mathrm{~m}$ long and $15.26 \mathrm{~mm}$ diameter thread steel rock 


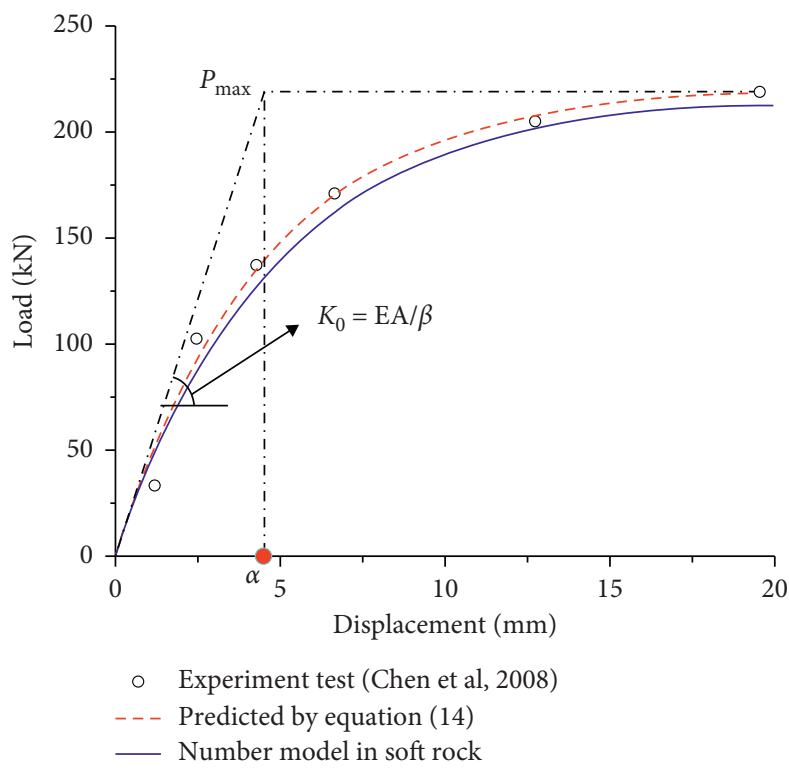

(a)

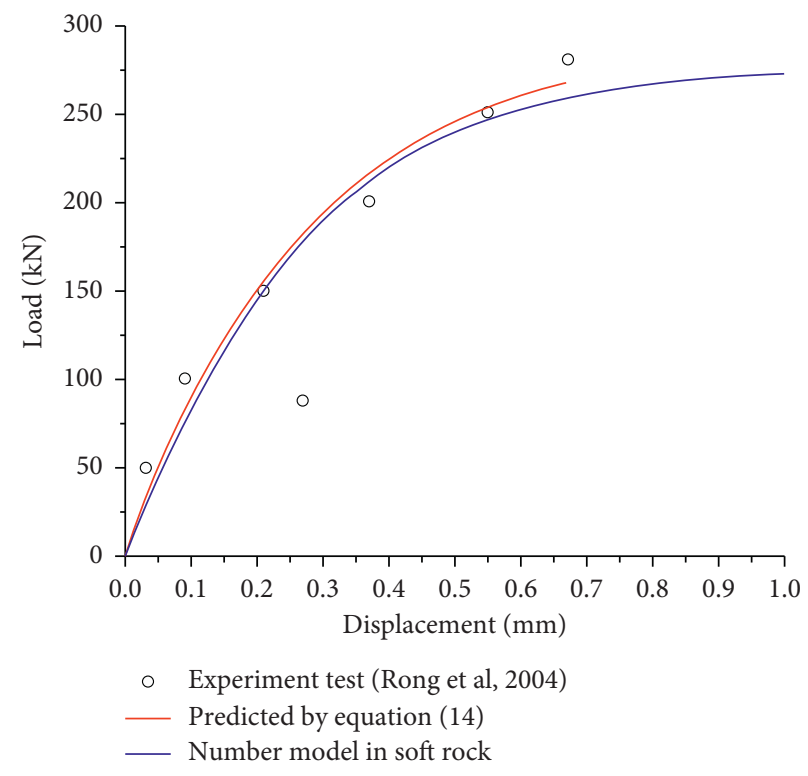

(b)

Figure 5: Comparison of load-displacement curves between the analytical model predicted by equation (14), the numerical model, and the experiment test in (a) soft rock and (b) hard rock.

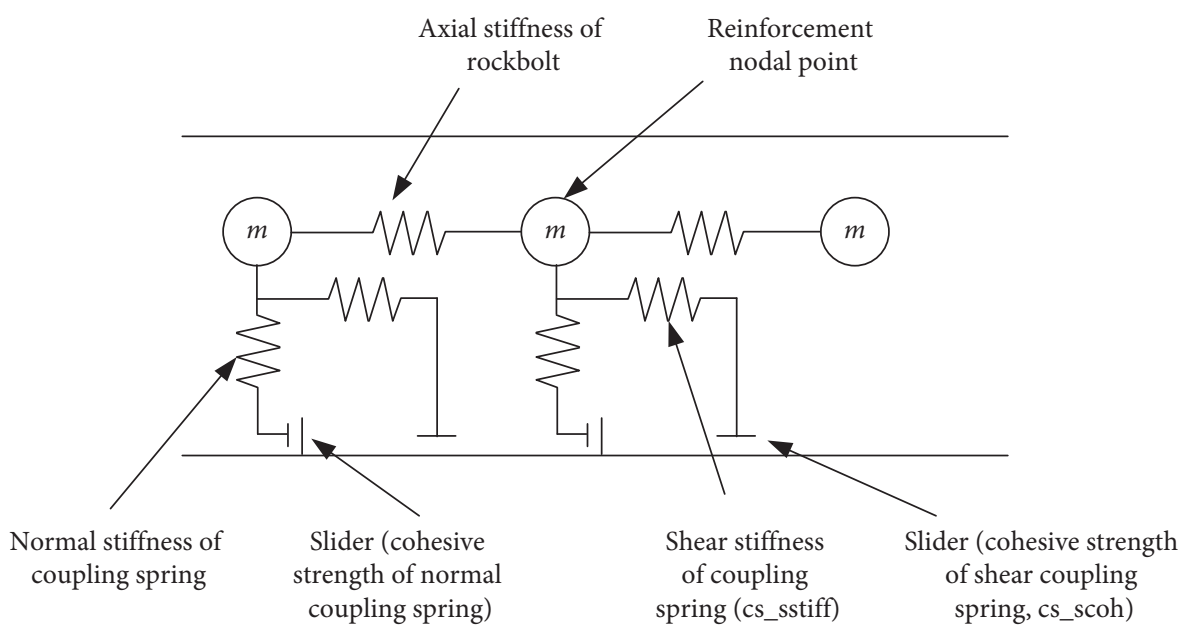

Figure 6: Mechanical properties of the interaction between pile element and surrounding rock masses [38].

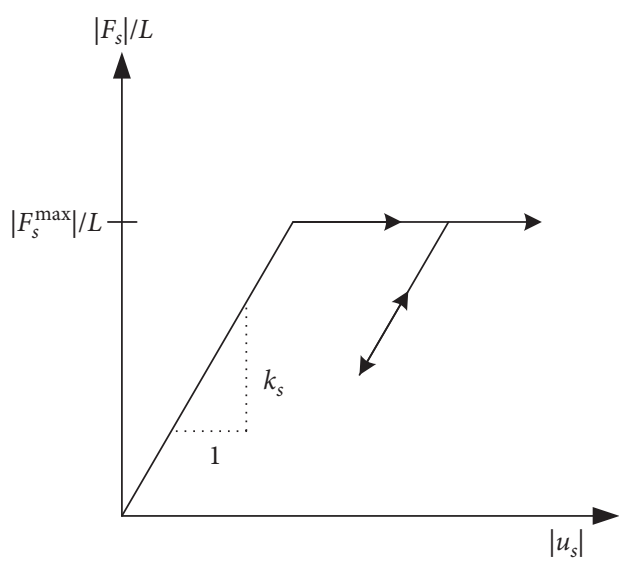

(a)

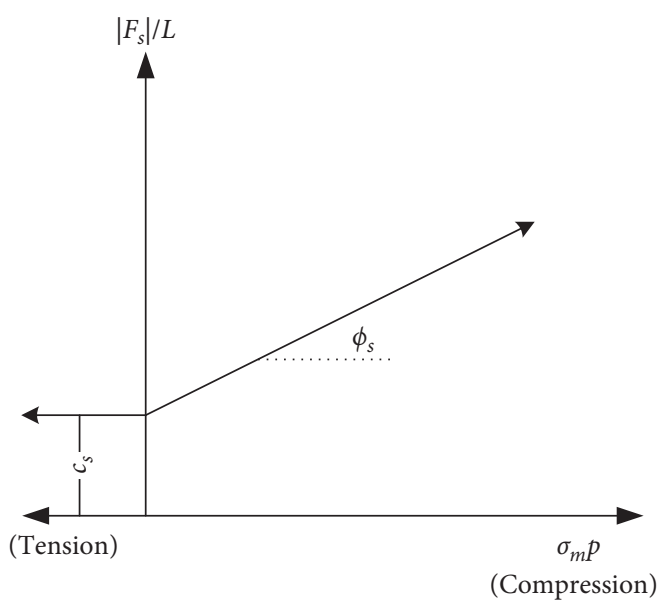

(b)

Figure 7: Behavior of shear coupling springs of pile element [38]. (a) Shear force/length versus relative shear displacement $u_{\mathrm{s}}$. (b) Shearstrength criterion. 
bolt grouted in soft rock. According to the load-displacement data from the pull-out test in the soft and hard rock, the data are fitted by equation (14) to obtain $\alpha=4.5455 \mathrm{~mm}$, $\beta=751.52 \mathrm{~mm}$ in soft rock and $\alpha=0.2169 \mathrm{~mm}$, and $\beta=131.58 \mathrm{~mm}$ in hard rock. Substituting $\alpha$ and $\beta$ into equation (13) respectively obtained the bond-slip relationship of the bond interface in soft rock and hard rock, as shown in Figure 8. The bond-slip curves show obvious nonlinear characteristics of the bond interface. The peak shear stress points $m(3.2,1.54)$ and $m^{\prime}(0.14,5.25)$ indicate the initiation of a softening state. The points $n(20,0.07)$ and $n$ ' $(1.0,0.21)$ indicate the initiation of a debonding state. A set of key points in Figure 8 were selected from the bond-slip curves for the pile structural element of the Flac3D model and the shear stress was transferred into cs_scoh by using equation (21). This model was rewritten and implemented as a subroutine by FISH language in Flac3D Version 5.0.

The surrounding rock masses are modeled using an isotropic elastic model; the rock bolt is assumed to be elastic and does not consider the yielding or breaking. Hence, the tensile yield strength was set to a large value. The numerical model is a rectangular parallelepiped with a size of $5 \mathrm{~m} \times 0.3 \mathrm{~m} \times 0.3 \mathrm{~m}$ (length $\times$ width $\times$ height) for soft rock and $1 \mathrm{~m} \times 0.3 \mathrm{~m} \times 0.3 \mathrm{~m}$ for hard rock. The velocity of grid points is fixed in the $y$-directions on the $y=0$ boundary and the other boundaries are free. To simulate the tensile load, a constant velocity $v=1 \times 10^{-7} \mathrm{~m}$ per step is applied to the load end (i.e., node 1 of pile element). Then, the pull-out displacement is equal to the product of the steps and the constant velocity $\nu$. The pile structure elements of Flac3D are used to simulate the rock bolt. The anchor length of hard rock is $1.0 \mathrm{~m}$, the anchorage length of soft rock is $5 \mathrm{~m}$, and both of the exposed sections are $0.05 \mathrm{~m}$, which is divided into 42 and 202 units, respectively; each unit is $0.025 \mathrm{~m}$, as shown in Figure 9. The parameters taken from the pile structural unit are shown in Table 1.

The pull-out load versus displacement curve is obtained by monitoring the axial force of pile element node 1 and the displacement of pile element node 3 . The load-displacement curve made by the Flac3D simulation is compared with the results from the pull-out tests and the analytical model in Figure 5. A very good agreement between the results from the Flac3D simulation, the pull-out testes, and the analytical model can be seen. The shear stress in the coupling spring versus shear displacement curves for nodes $4,10,30$, and 42 in hard rock and nodes 4, 34, 144, and 202 in soft rock were monitored and used to compare with the input bond-slip relationship as shown in Figure 8. It can be seen that the different nodes along the rock bolt have the same bond-slip relationship and have a good agreement with the input bond-slip relationship.

In order to analyze the load transfer mechanism and shear stress distributions along the rock bolt as well as the load-displacement response of the anchoring system, the following is the analysis of pull-out simulation data for hard rock and soft rock. The load-displacement curves are divided into the following three states: linear state I (OA segment), nonlinear stage II (AB segment), and softening and debonding stage III (BC segment), as shown in Figure 10.
The distributions of the shear stress along the bolt-grout interface and the axial force along the bolt at various load levels are also presented in Figure 11:

Linear stage I (OA segment): when the pulling load is $100 \mathrm{kN}$ in hard rock and $50 \mathrm{kN}$ in soft rock, the shear stress is less than the interfacial maximum bond strength of $5.25 \mathrm{MPa}$ and $1.54 \mathrm{MPa}$ (see $m^{\prime}$ and $m$ point in Figure 8). The maximum shear stress and the maximum axial force are located at the loading end and gradually decay exponentially toward the free end. The OA segment of the load-displacement curves exhibits an almost linear increase.

Nonlinear stage II (AB segment): with the increase of the pulling load at the loading end, such as the pulling load, is $200 \mathrm{kN}, 250 \mathrm{kN}$ in hard rock and $100 \mathrm{kN}$, $150 \mathrm{kN}$ in soft rock; the shear stress at the loading end exceeds the maximum bond strength of the bond interface. The local softening and debonding of bond interface will occur. The shear stress curves gradually evolve into a unimodal curve and the peak point continuously transfers to the deep part. The axial force curves gradually show an anti- "S" type change trend decay. The attenuation is gentle near the loading end and then exponentially decays. The AB segment of the load-displacement curves shows that the load continues to increase, but the growth rate becomes slower.

Softening and debonding stage III (BC segment): when the peak shear stress transmits to the anchor end; the shear stress cannot further transfer to the deep part due to the limitation of the anchor length. Once the peak shear stress at the free end exceeds maximum bond strength of bond interface, subsequent softening and debonding will occur rapidly. The shear stress of the bond interface becomes a constant and the entire bond interface only has the frictional resistance. For example, when the pulling load is $25 \mathrm{kN}$ in hard rock and $25 \mathrm{kN}$ in soft rock, the shear stress curves of the bond interface appear as a straight line parallel to the $x$-axis, and the axial force curve is linear decreasing monotonically. It should be specially noted that due to the debonding of the bond interface, the load-displacement curves suddenly drop. The elastic energy stored in the rod body loses the constraint and is released suddenly, and the retraction deformation of the bolt causes the axial force to become negative, as shown by the red dotted box in Figure 10.

\section{Numerical Calculation Model and Scheme Design}

The load transfer of rock bolt is closely related to the lithology and the occurrence state of rock strata. This section presents analysis of load transfer mechanism, shear stress distributions along the rock bolt, and the load-displacement response of the anchoring system in soft and hard composite rock strata (lithological sequences, layer thickness ratio, and layer numbers). Five simulation schemes were designed as shown in Table 2. The model size is $1 \mathrm{~m} \times 0.3 \mathrm{~m} \times 0.3 \mathrm{~m}$ 


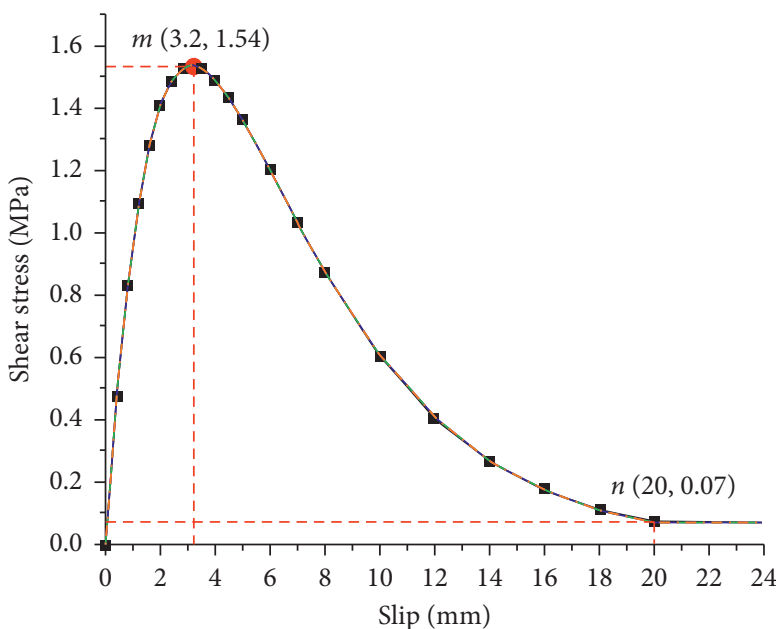

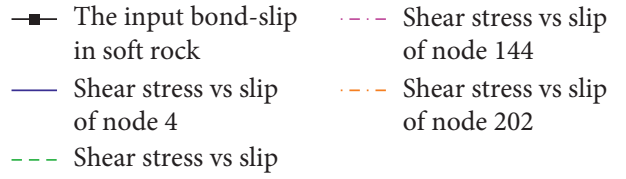
of node 34

(a)

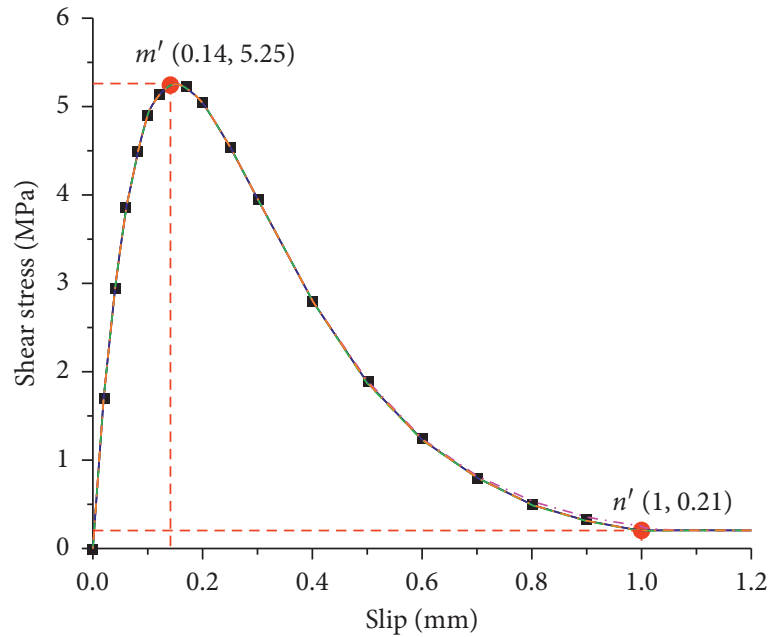

$\begin{array}{ll}\rightarrow-\begin{array}{l}\text { The input bond-slip } \\ \text { in hard rock }\end{array} & \begin{array}{l}\text { Shear stress vs slip } \\ \text { of node } 30\end{array} \\ -\begin{array}{l}\text { Shear stress vs slip } \\ \text { of node } 4\end{array} & \text { of node } 42 \\ --- & \begin{array}{l}\text { Shear stress vs slip } \\ \text { of node } 10\end{array}\end{array}$

(b)

Figure 8: Comparison of bond-slip curves at different nodes with the input bond-slip relationship in (a) soft rock and (b) hard rock.

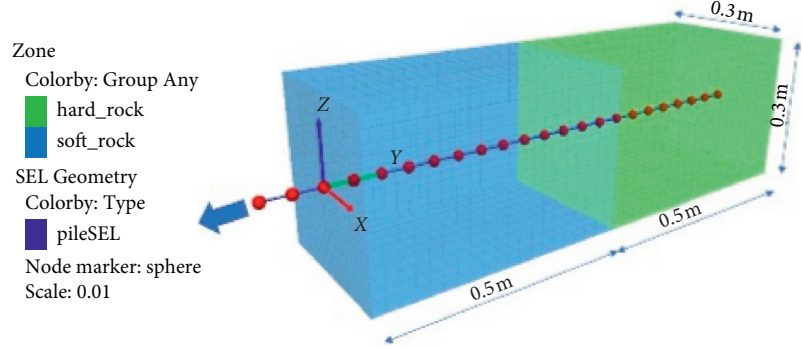

(a)

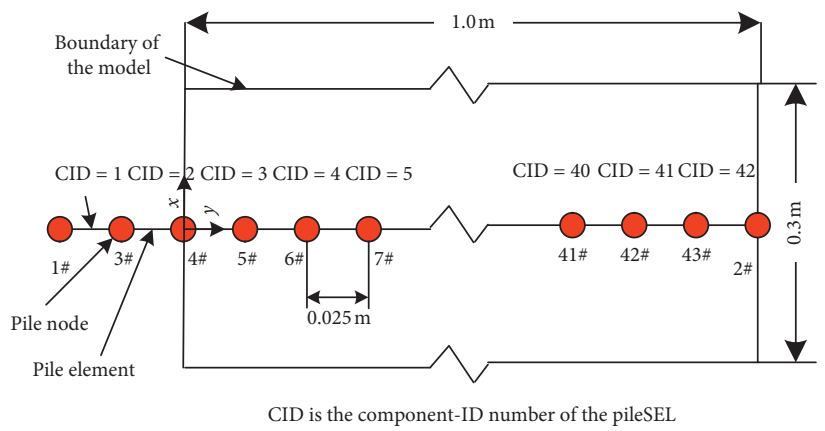

(b)

Figure 9: Schematic diagram of numerical simulation for the pull-out test. (a) Numerical model. (b) Pile elements, CID numbers, and node numbers in hard rock.

TABLE 1: Simulation model input parameters for pile elements.

\begin{tabular}{lcccccc}
\hline Item & $\begin{array}{c}\text { Elastic modulus } \\
(\mathrm{GPa})\end{array}$ & $\begin{array}{c}\text { Cross-sectional area } \\
\left(\mathrm{m}^{2}\right)\end{array}$ & $\begin{array}{c}\text { Perimeter of the } \\
\text { rockbolt }(\mathrm{m})\end{array}$ & $\begin{array}{c}\text { Tensile yield } \\
\text { strength }(\mathrm{N})\end{array}$ & $\begin{array}{c}\text { cs_sstiff } \\
\left(\mathrm{N} \cdot \mathrm{m}^{2}\right)\end{array}$ & $\begin{array}{c}\text { Number of pile } \\
\text { elements }\end{array}$ \\
\hline $\begin{array}{l}\text { Hard } \\
\text { rock }\end{array}$ & 210 & $803.84 \times 10^{-6}$ & $100.48 e-3$ & $1 \times 10^{10}$ & $1 e 10$ & 42 \\
Soft rock & 210 & $182.8 e-6$ & $47.92 e-3$ & $1 \times 10^{10}$ & $1 e 8$ & 202 \\
\hline
\end{tabular}

(length $\times$ width $\times$ height). The length of the anchorage section is $1 \mathrm{~m}$ and the exposed section is $0.05 \mathrm{~m}$. The rock bolt element is divided into 42 units; each unit is $0.025 \mathrm{~m}$. The corresponding bond-slip relationship of soft rock and hard rock is assigned to pile structural elements, respectively, and the parameters of the pile structural elements are shown in Table 3.

\section{Calculation Results and Discussion}

5.1. Lithological Sequences. The anchoring system bear the load from the loading end firstly and gradually transfers to the deep. For soft and hard composite rock strata, the lithological sequences will affect the bearing capacity of the anchoring system. In this section, the composite rock strata 


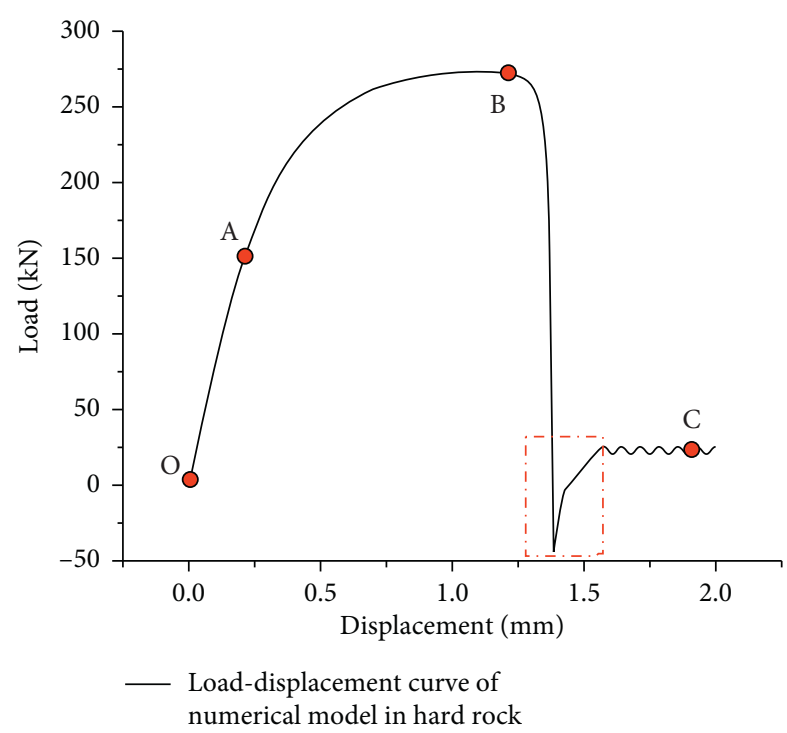

(a)

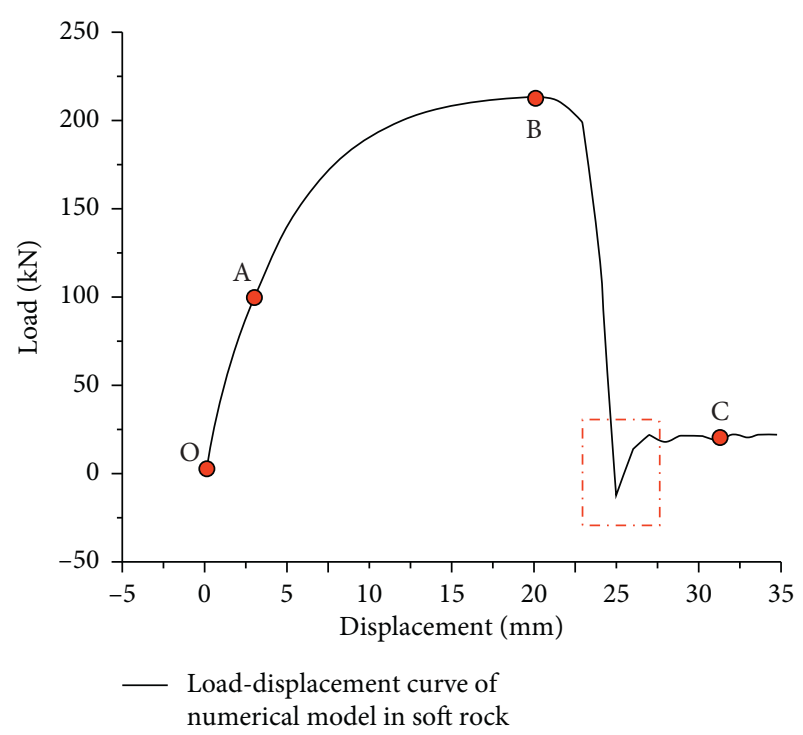

(b)

FIGURE 10: Load-displacement curves of numerical model (a) in hard rock and (b) soft rock.

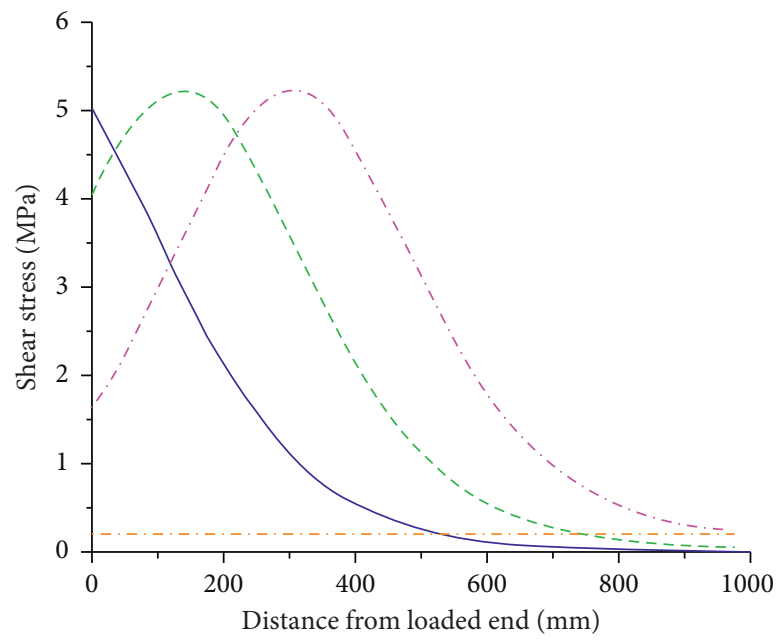

— $100 \mathrm{kN}$ in hard rock _... $250 \mathrm{kN}$ in hard rock $\ldots-200 \mathrm{kN}$ in hard rock _... $25 \mathrm{kN}$ in hard rock

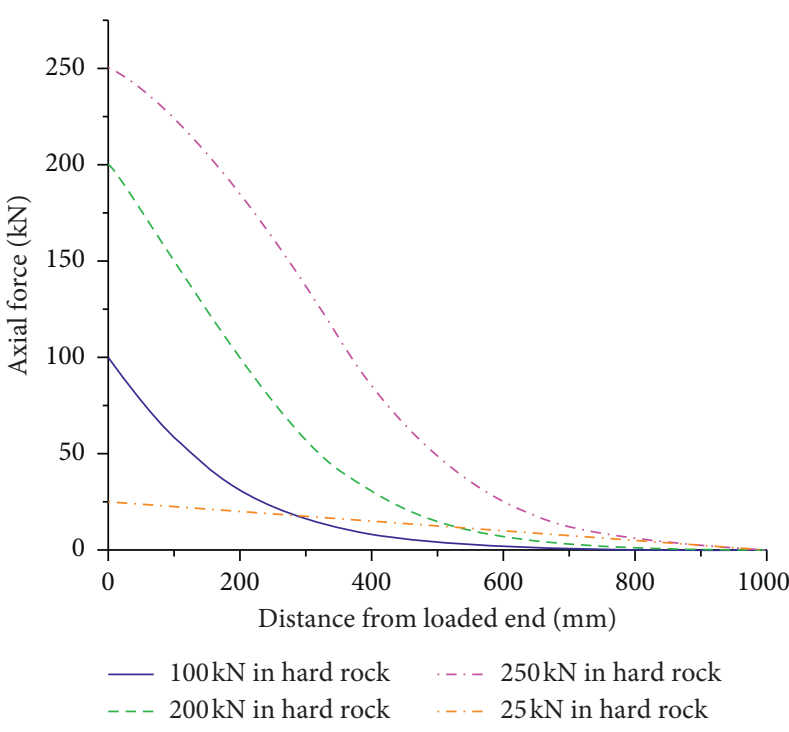

(a)

Figure 11: Continued. 

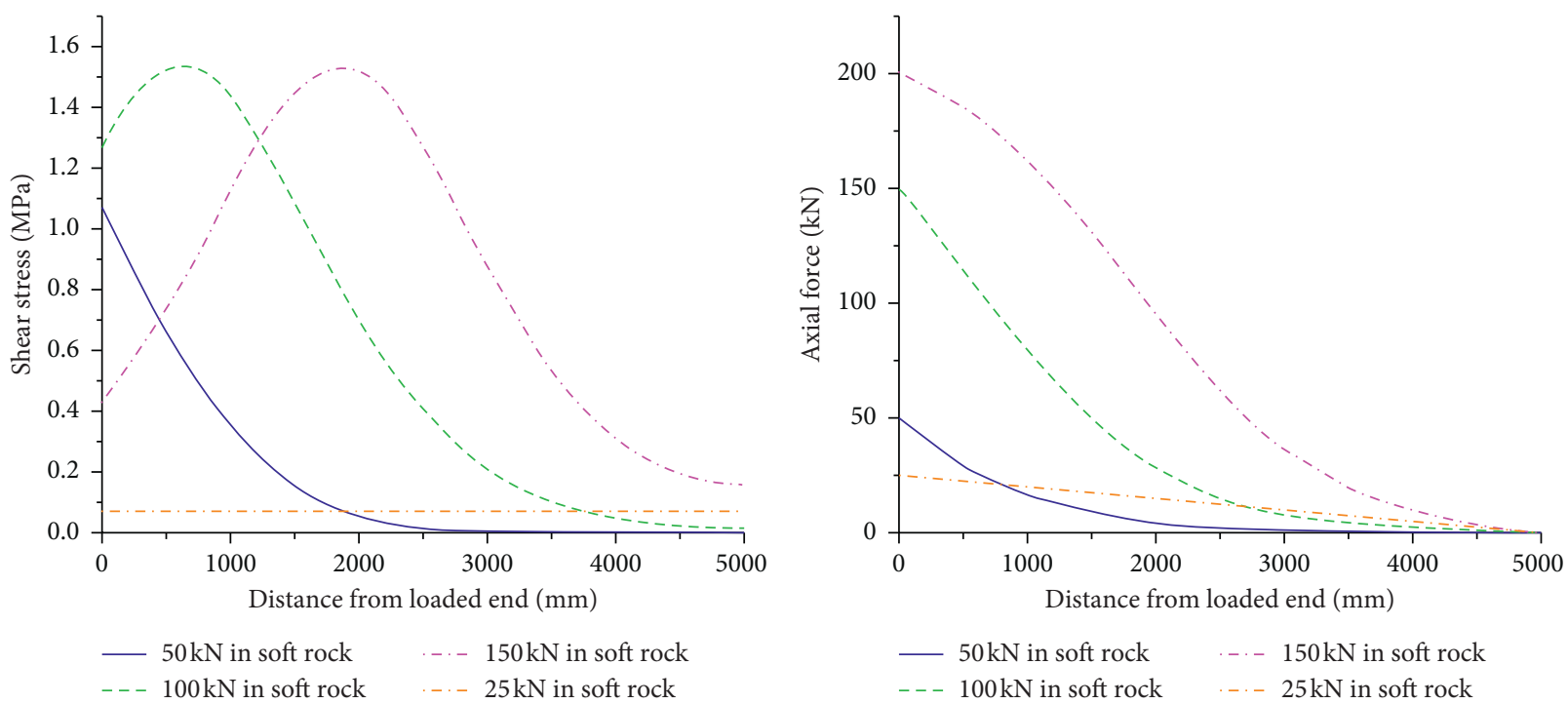

(b)

FIgURE 11: Shear stress (left) and axial force (right) distribution curves along the rock bolt in (a) hard rock and (b) soft rock.

TABLE 2: Numerical simulation schemes.

\begin{tabular}{|c|c|c|c|c|}
\hline \multicolumn{2}{|c|}{ Project numbers } & Layer numbers & Lithological sequences & Layer thickness ratio \\
\hline \multicolumn{2}{|l|}{ Project 1} & 1 & Soft (S) & - \\
\hline \multirow[t]{2}{*}{ Project 2} & & 1 & Hard $(\mathrm{H})$ & - \\
\hline & Project 3-1 & & & $\mathrm{SH}=3: 7$ \\
\hline \multirow{3}{*}{ Project 3} & Project 3-2 & 2 & Shallower-soft and deeper-hard (SH) composite rock strata & $\mathrm{SH}=5: 5$ \\
\hline & Project 3-3 & & & $\mathrm{SH}=7: 3$ \\
\hline & Project $4-1$ & & & $\mathrm{HS}=3: 7$ \\
\hline \multirow[t]{3}{*}{ Project 4} & Project 4-2 & 2 & Shallower-hard and deeper-soft (HS) composite rock strata & $\mathrm{HS}=5: 5$ \\
\hline & Project $4-3$ & & & $\mathrm{HS}=7: 3$ \\
\hline & Project 5-1 & 4 & SHSH & $\mathrm{SH}=1: 1$ \\
\hline \multirow[t]{2}{*}{ Project 5} & Project 5-2 & 6 & SHSHSH & $\mathrm{SH}=1: 1$ \\
\hline & Project 5-3 & 8 & SHSHSHSH & $\mathrm{SH}=1: 1$ \\
\hline
\end{tabular}

TABLE 3: Simulation model input parameters for pile elements.

\begin{tabular}{lccccr}
\hline $\begin{array}{l}\text { Elastic modulus } \\
(\mathrm{GPa})\end{array}$ & $\begin{array}{c}\text { Cross-sectional } \\
\text { area }\left(\mathrm{m}^{2}\right)\end{array}$ & $\begin{array}{c}\text { Perimeter of the } \\
\text { rockbolt }(\mathrm{m})\end{array}$ & $\begin{array}{c}\text { Tensile yield } \\
\text { strength }(\mathrm{N})\end{array}$ & $\begin{array}{c}\text { Number of } \\
\text { pile elements }\end{array}$ & $\begin{array}{c}\text { cs_sstiff } \\
\left(\mathrm{N} \cdot \mathrm{m}^{-2}\right)\end{array}$ \\
\hline 210 & $803.84 \times 10^{-6}$ & $100.48 \times 10^{-3}$ & $1.5 \times 10^{10}$ & 42 & $\begin{array}{c}\text { Hard rock }: 1 e 10 \\
\text { soft rock: } 1 e 8\end{array}$ \\
\hline
\end{tabular}

of two layers are taken as an example composed of soft rock and hard rock. The thickness of the soft rock layer and the hard rock layer are both $0.5 \mathrm{~m}$. Rock strata at the anchoring start are called shallow surrounding rock, and that at the anchoring end is called deep surrounding rock. Then, the soft and hard composite rock strata are divided into shallower-soft and deeper-hard composite rock strata (simplified to SHCRS) and shallower-hard and deeper-soft composite rock strata (simplified to HSCRS). The effect of lithological sequences is analyzed on the load transfer mechanism and shear stress distributions along the rock bolt as well as the load-displacement response of the anchoring system.
It can be seen from Figure 12 that the load-displacement curve of the SHCRS has a smaller initial stiffness than that of the HSCRS, but the peak load and the displacement at the peak load have obvious advantages. The peak load of HSCRS is $227.8 \mathrm{kN}$, and the displacement at the peak load is $0.5 \mathrm{~m}$; the peak load of the SHCRS is $252.2 \mathrm{kN}$ and the contrast increased by $10.7 \%$. The displacement at the load peak of the SHCRS is $1.4 \mathrm{~mm}$; the contrast increased by $180 \%$. The main reason is that the shallow soft rock segment bears the load firstly and consumes partial load. The hard rock segment mainly bears the load. Therefore, the bearing capacity of the anchorage system increases as a whole. The bond strength of the soft rock segment is weak in SHCRS, but it can provide a 


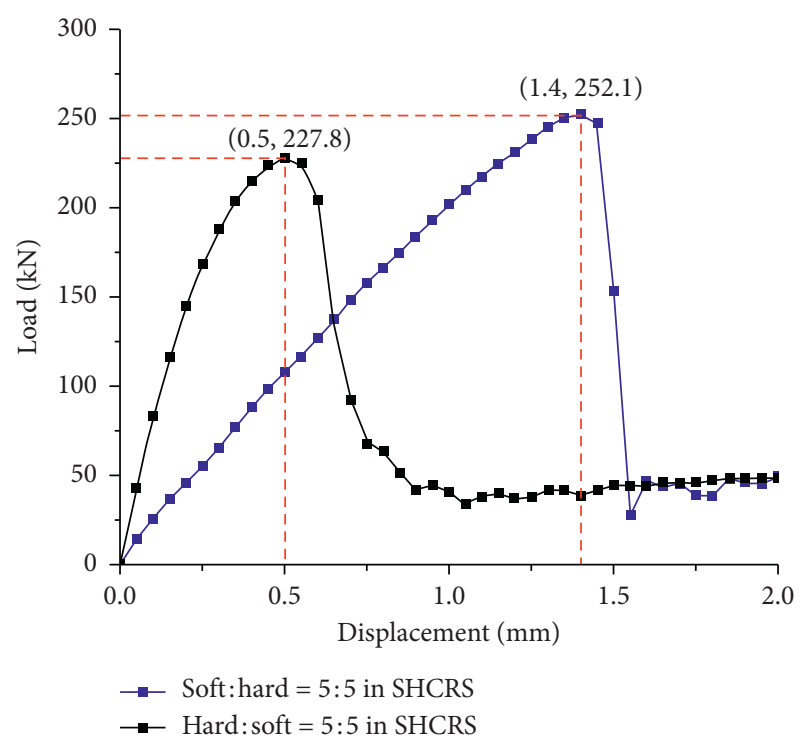

FIGURE 12: Load-displacement comparison curves in SHCRS and HSCRS.

larger deformation, thus increasing the deformation of the anchoring system as a whole. In the actual engineering, the support design for the soft and hard composite rock strata and the end of the rock/cable bolts can be anchored in the hard rock as much as possible.

Figure 13 shows the distributions of the interfacial shear stress and the axial force along the bolt at various load levels in SHCR and HSCRS:

Linear stage: when the pulling load is $50 \mathrm{kN}$, the peak axial force is at the loading end and gradually decays along the rock bolt to the deep. Both the shear stress curves and the axial force curves show abrupt change at the soft-hard/hard-soft interface. As for the SHCRS, the soft rock segment bears the load firstly and the initial stiffness of the load-displacement curve and the axial force attenuation gradient is small due to the weak bond strength. The axial force attenuation gradient increases significantly due to the strong bond strength in the hard rock segment. As for the HSCRS, the hard rock segment bears the load firstly and the initial stiffness of the load-displacement curve and the axial force attenuation gradient is large, due to the strong bond strength. The shallow hard rock segment mainly carries the load, the relative slip of the deep soft rock segment is very small, and the shear stress of the bond interface is almost zero.

Nonlinear stage: when the pulling load is $200 \mathrm{kN}$, the shear stress curve of bond interface shows a single peak distribution and the peak shear stress gradually transfers to the deep. Since the soft rock segment in SHCRS consumes a partial load, the interfacial shear stress of the hard rock segment enters the plasticsoftening stage later in SHCRS than that in HSCRS. The interfacial shear stress of the soft rock segment in HSCRS is obviously smaller than that in SHCRS and is almost zero, due to the hard segment bear most of the load. Once the anchoring failure occurs in the shallow hard rock segment, it is impossible for the deep soft rock segment to continue to bear the higher stress. Therefore, the deep soft rock segment of HSCRS has little effect on the bearing capacity of the anchorage system, which is equivalent to reducing the length of the anchorage segment.

Softening and debonding stage: the hard rock segment of SHCRS and HSCRS have been decoupled, the shear stress is a constant, and the axial force curve linearly attenuated, indicating that only the frictional resistance exists at the bond interface. Since the relative displacement of the anchoring interface in the soft rock segment has not yet reached the displacement at the peak load $3.2 \mathrm{~mm}$ (see Figure 9(a)). The anchoring interface in soft rock is in the elastic stage. The interfacial shear stress curves of the soft rock segment monotonously attenuate.

\subsection{Layer Thickness Ratio}

5.2.1. Influence of Different Thickness Ratios of SHCRS. Figure 14 gives the influences of the soft-to-hard thickness ratio in SHCRS on the load-displacement response. As the soft-to-hard thickness ratio increased, the farther the hard rock layer is from the loading end, the smaller the initial stiffness of the load-displacement curve is. The smaller the thickness of hard rock is, the smaller peak load of the loaddisplacement curve is.

Figure 15 shows the distributions of the interfacial shear stress and the axial force along the bolt at various load levels of soft-to-hard thickness ratios $(7: 3,5: 5$, and $3: 7)$ in SHCRS:

Linear stage: when the pulling load is $50 \mathrm{kN}$, the bond interface of both soft rock and hard rock are in the elastic stage; the axial force and shear stress curves decay monotonically. As the soft-to-hard thickness ratio increases, the axial force attenuation gradient increases. The soft rock thickness increases, which will inevitably consume more load, resulting in lower initial load and shear stress of hard rock segment. That is to say, the smaller the soft-to-hard thickness ratio, the earlier the shear stress of the hard rock segment enters the softening stage, and the peak shear stress gradually transfers to the deep.

Nonlinear stage: when the pulling load is $180 \mathrm{kN}$, the distribution of axial force along the rock bolt is similar to that in the linear stage. The interfacial shear stress of the soft rock segment does not reach the maximum bond strength and is still in the elastic stage. The shear stress curves of the hard rock segment are unimodal distribution and the peak shear stress transfer to the deep, which has entered the softening stage. As the hard rock thickness decreases, the shear stress at the free end increases. For example, when the soft-to-hard thickness ratio is $7: 3$, the shear stress at the free end is $4.43 \mathrm{MPa}$, which reaches $84.2 \%$ of the peak shear stress and thus leads to the lowest peak load of anchoring system. 

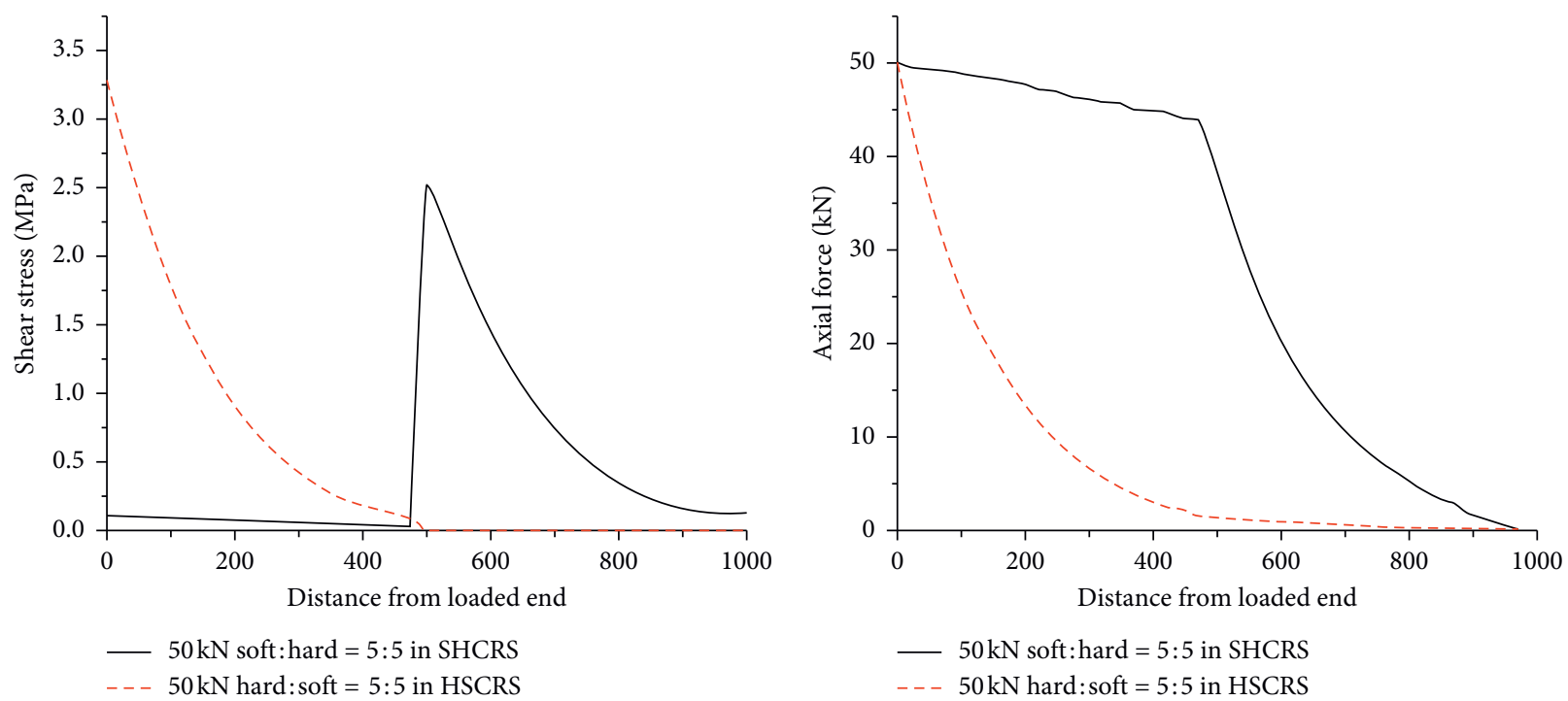

(a)
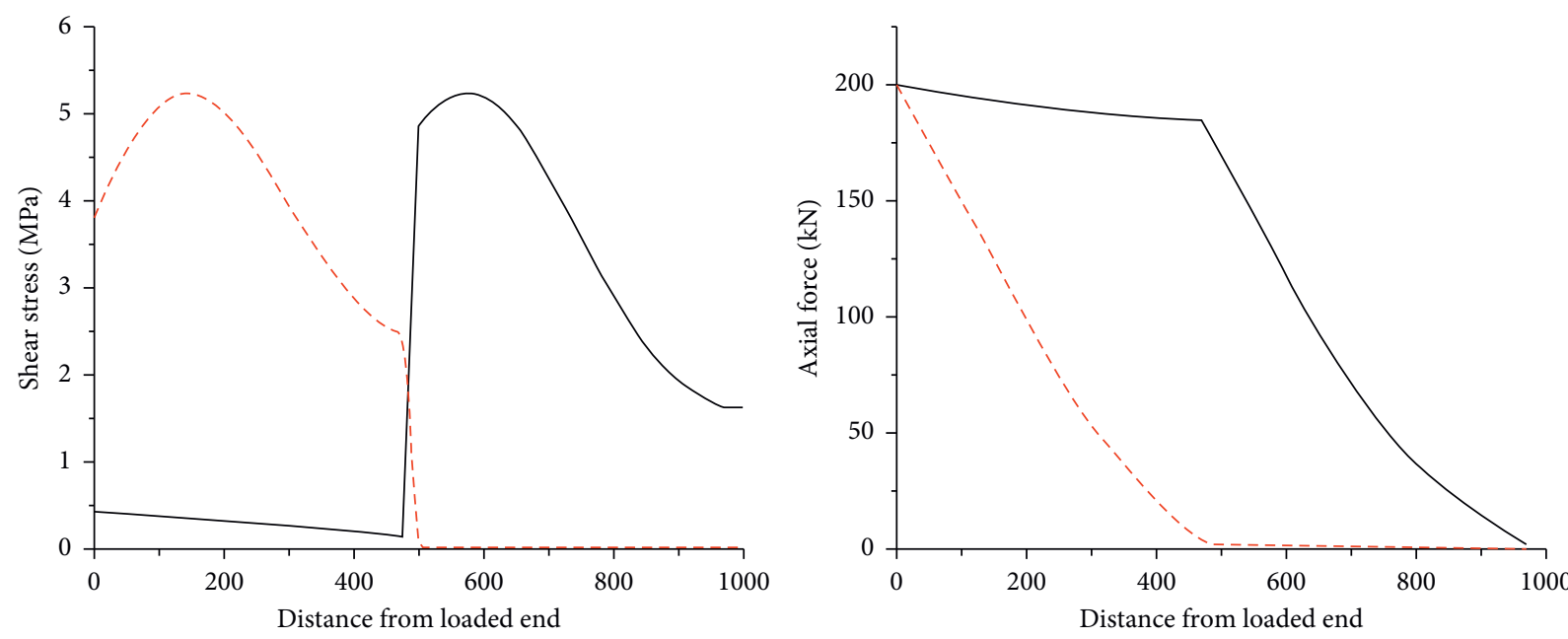

- $200 \mathrm{kN}$ soft:hard $=5: 5$ in SHCRS

— $200 \mathrm{kN}$ soft:hard $=5: 5 \mathrm{in} \mathrm{SHCRS}$

- - $200 \mathrm{kN}$ hard: $\mathrm{soft}=5: 5 \mathrm{in}$ HSCRS

$---200 \mathrm{kN}$ hard: soft $=5: 5 \mathrm{in}$ HSCRS

(b)
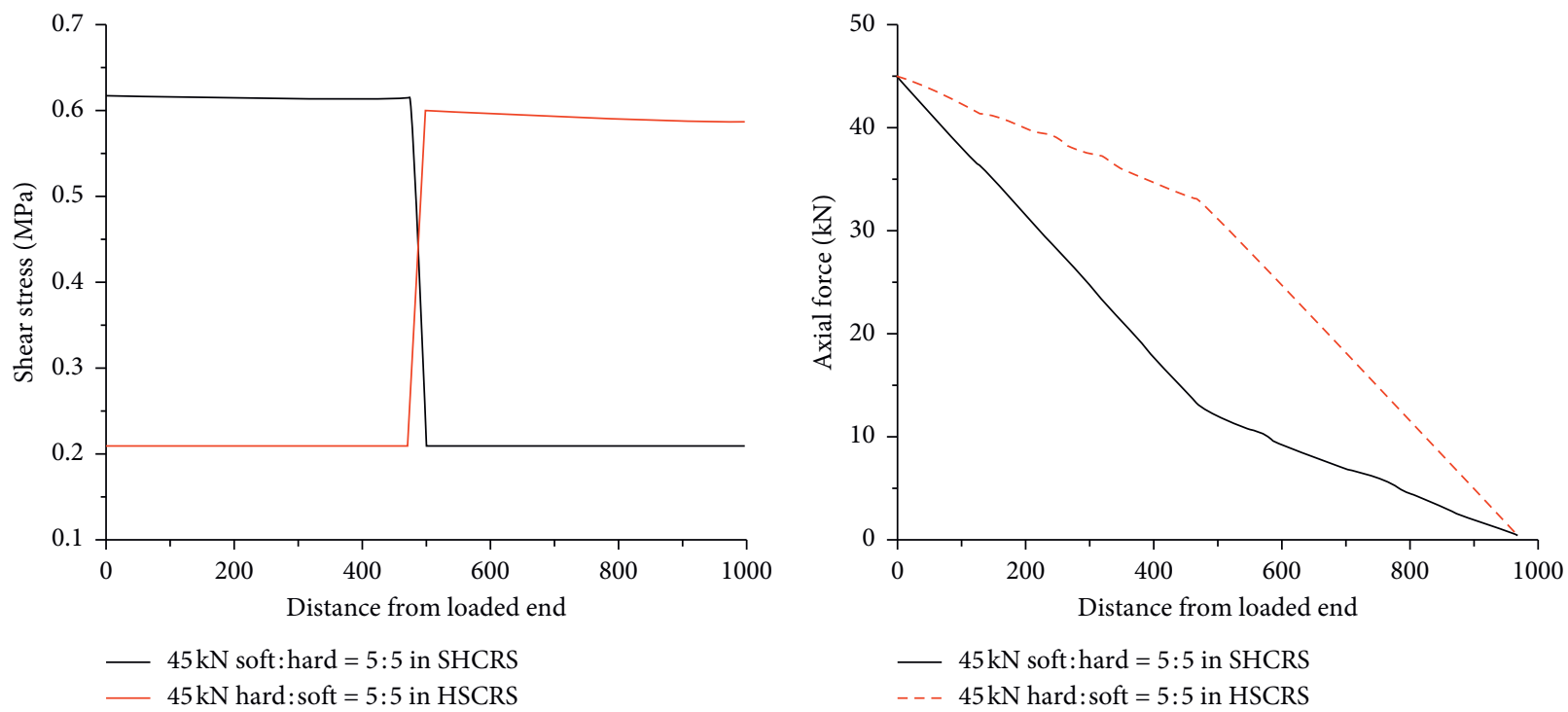

(c)

FIGURE 13: Shear stress (left) and axial force (right) distributions curves in SHCRS and HSCRS. (a) Linear stage. (b) Nonlinear stage. (c) Softening and debonding stage. 


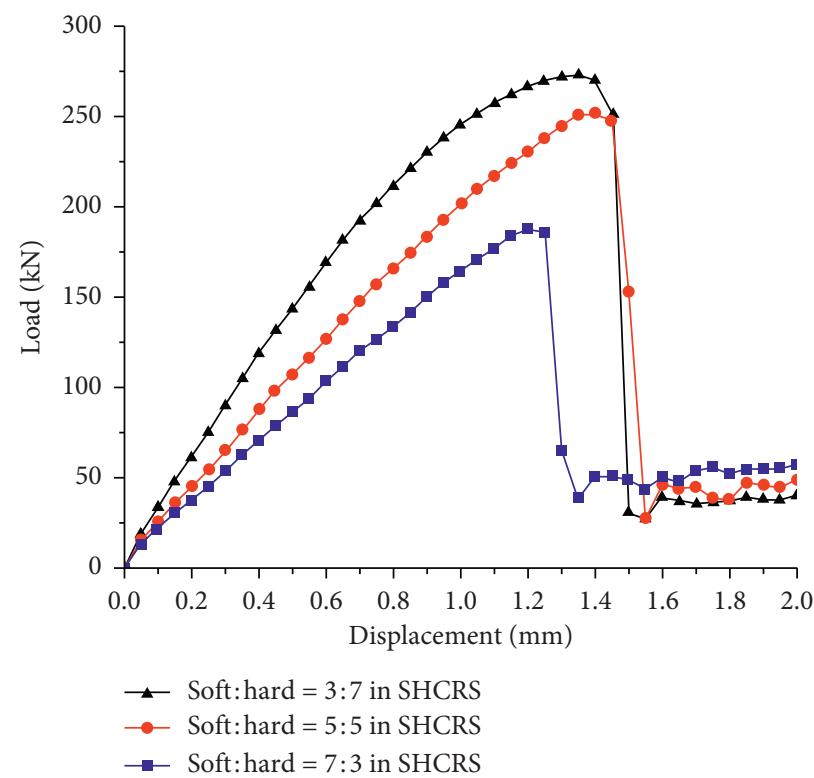

FIGURE 14: Comparison of load-displacement curves of soft-to-hard thickness ratios $(3: 7,5: 5$, and $7: 3)$ in SHCRS.

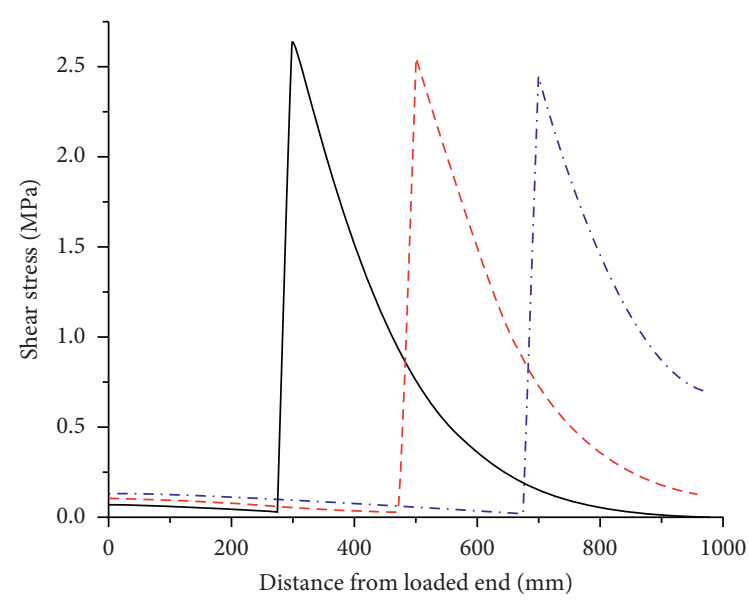

— $50 \mathrm{kN}$ soft:hard $=3: 7$ in SHCRS

- - $50 \mathrm{kN}$ soft: hard $=5: 5$ in SHCRS

... $50 \mathrm{kN}$ soft: hard $=7: 3$ in SHCRS

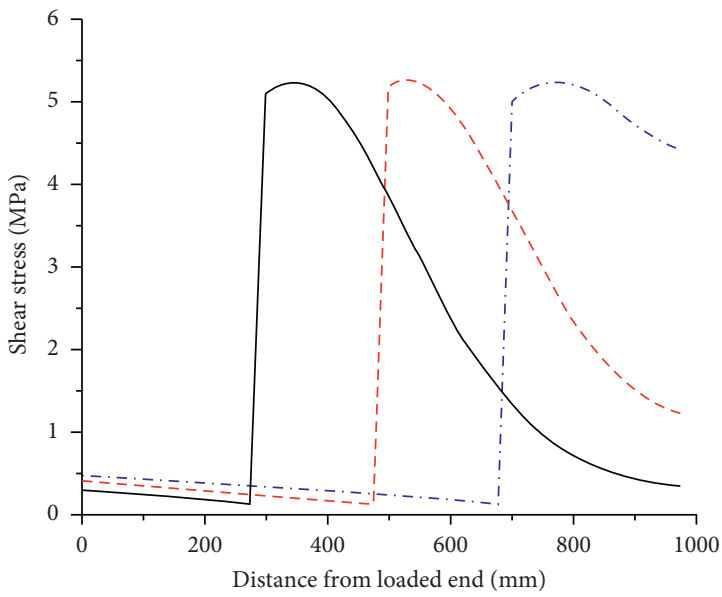

$180 \mathrm{kN}$ soft: hard $=3: 7$ in SHCRS

- - $180 \mathrm{kN}$ soft: hard $=5: 5$ in SHCRS

-. $180 \mathrm{kN}$ soft: hard $=7: 3$ in SHCRS

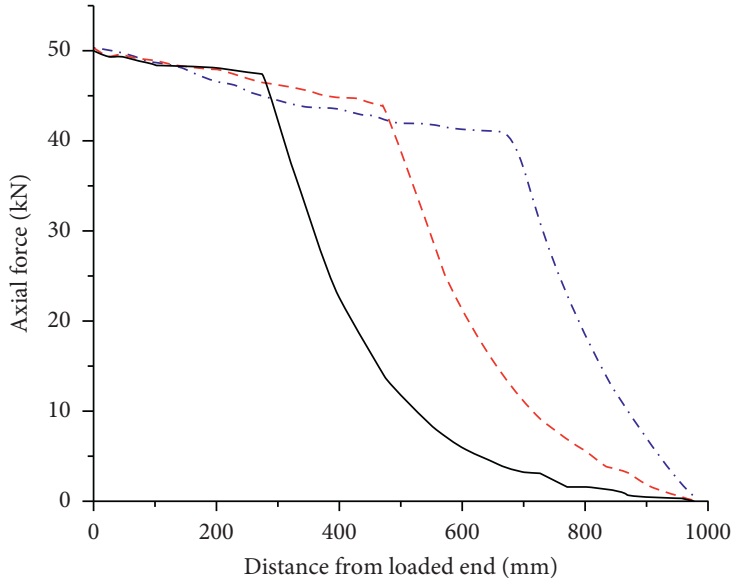

$50 \mathrm{kN}$ soft: hard $=3: 7$ in SHCRS

- - $50 \mathrm{kN}$ soft: hard $=5: 5$ in SHCRS

-. $50 \mathrm{kN}$ soft: hard $=7: 3$ in SHCRS

(a)

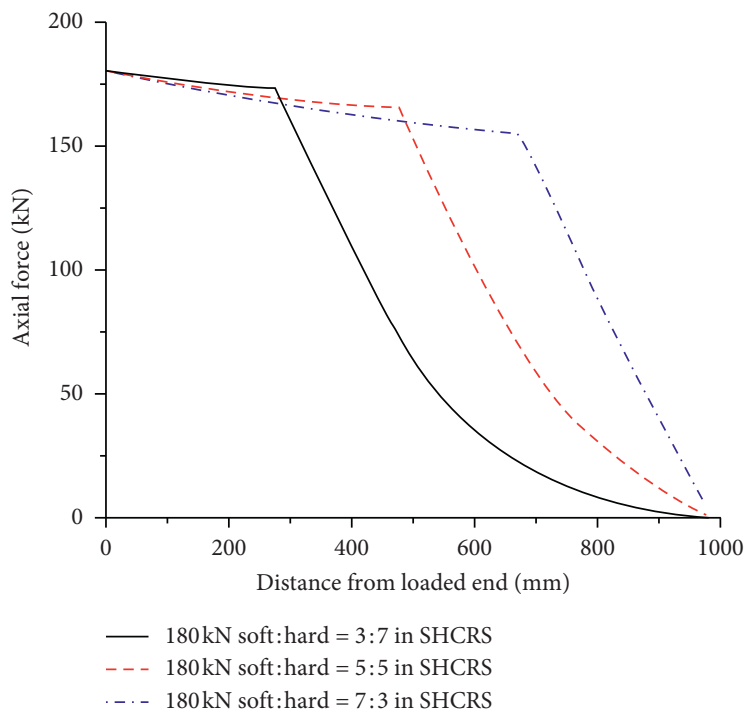

(b)

FIgURE 15: Continued. 

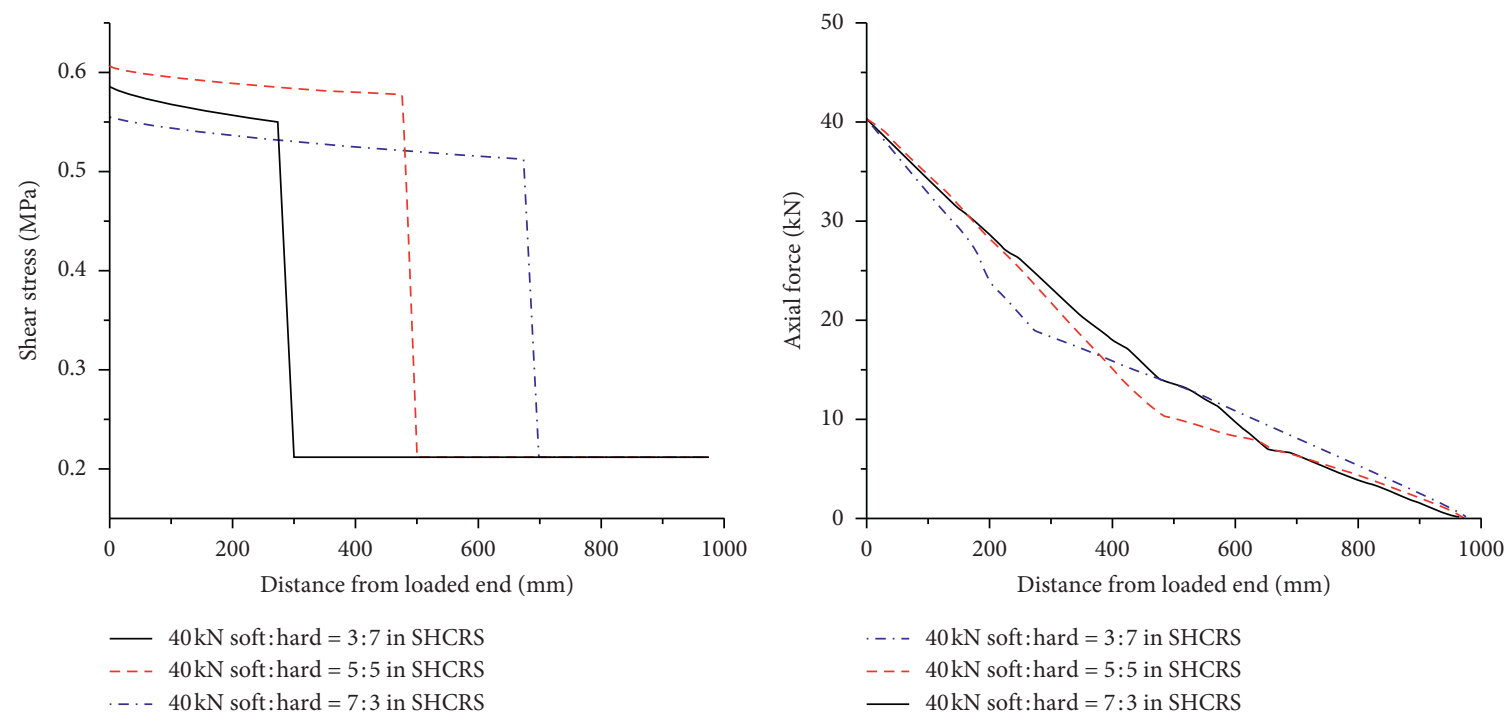

(c)

FIGURE 15: Shear stress (left) and axial force (right) distribution curves of soft-to-hard thickness ratios $(7: 3,5: 5,3: 7)$ in SHCRS. (a) Linear stage. (b) Nonlinear stage. (c) Softening and debonding stage.

Softening and debonding stage: when the pulling load is $40 \mathrm{kN}$, the hard rock segment has been decoupled, the interfacial shear stress value is constant, and the axial force linearly attenuates, indicating that there is only frictional resistance. The interfacial shear stress in soft rock segment has not reached the interfacial maximum bond strength. The anchoring interface in soft rock segment is in the elastic stage. The interfacial shear stress curves of the soft rock segment monotonously attenuate.

\subsubsection{Influence of Different Thickness Ratios of HSCRS.} Figure 16 gives the influences of the soft to hard thickness ratio in HSCRS on the load-displacement response. Due to the shallow hard rock segment bearing the load, firstly, the load-displacement curves exhibit the same initial stiffness under different hard to soft thickness ratios in HSCRS. As hard-to-soft thickness ratio increases, both the peak load and the displacement at the peak load increase.

Figure 17 shows the distributions of the interfacial shear stress and the axial force along the bolt at various load levels of soft-to-hard thickness ratios $(7: 3,5: 5,3: 7)$ in HSCRS:

Linear stage: when the pulling load is $100 \mathrm{kN}$, as hardto-soft thickness ratio increases, the shear stress attenuation gradient increases and the axial force attenuation gradient decreases of the hard rock segment. Since the shallow hard rock segment bears the main load, the relative slip of bond interface in deep soft rock segment is small, and the shear stress is almost zero.

Nonlinear stage: when the pulling load is $150 \mathrm{kN}$, the interfacial shear stress of hard rock segment has already been in the softening stage, the interfacial shear stress curves show a unimodal distribution, and the peak shear stress transfers to the deep constantly. The relative slip of bond interface in deep soft rock segment is

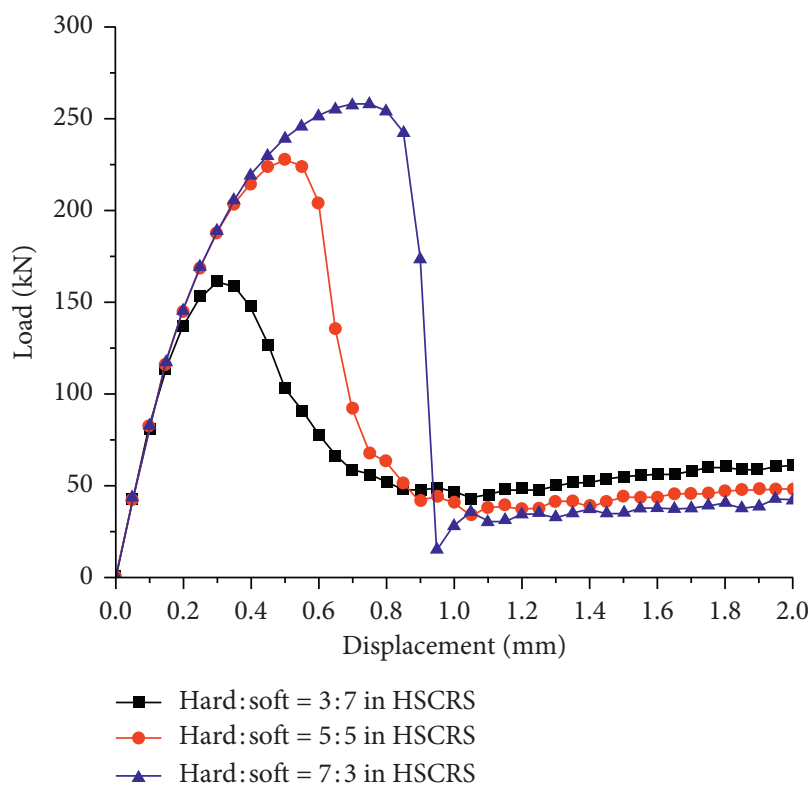

FIGURE 16: Comparison of load-displacement curves of soft to hard thickness ratios $(3: 7,5: 5$, and $7: 3)$ in HSCRS.

small, and the interfacial shear stress of soft rock segment is in linear stage. When hard-to-soft thickness ratio is $3: 7$, the interfacial shear stress has already entered the softening stage in the hard rock segment, the shear stress values of the entire hard rock segment are not much different, and the axial force shows almost linear attenuation. When hard-to-soft thickness ratio is $5: 5$ and $3: 7$, the interfacial shear stress of hard rock segment just enters the softening stage. When the pulling load is $220 \mathrm{kN}$, as the hard-to-soft thickness ratio increases, the peak shear stress can further transfer 

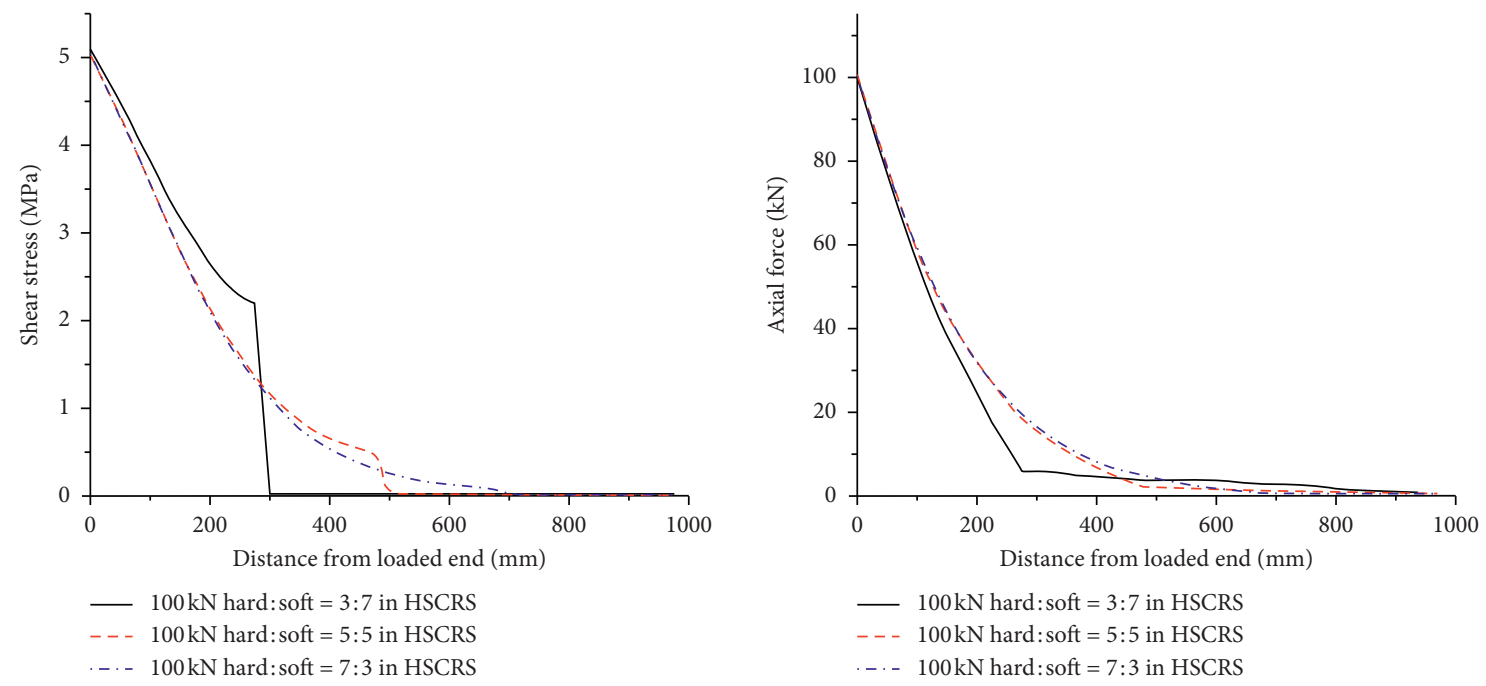

(a)
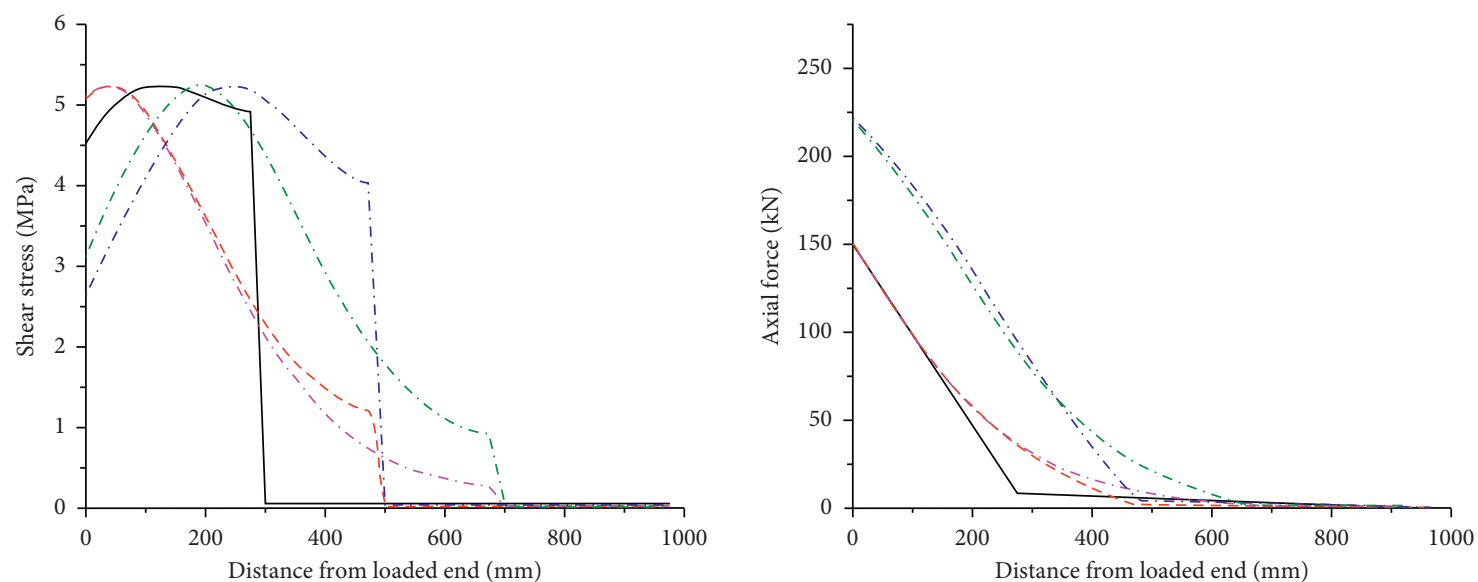

— $150 \mathrm{kN}$ hard: $\mathrm{soft}=3: 7 \quad \ldots \quad$ - $220 \mathrm{kN}$ hard $:$ soft $=5: 5$ in HSCRS in HSCRS

- - $150 \mathrm{kN}$ hard: $:$ oft $=5: 5 \quad \ldots \quad$ - $220 \mathrm{kN}$ hard $:$ off $=7: 3$ in HSCRS

in HSCRS

-. $150 \mathrm{kN}$ hard $: \mathrm{soft}=7: 3$

in HSCRS

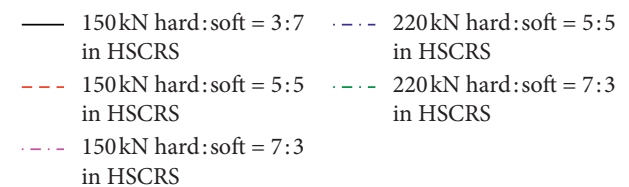

(b)
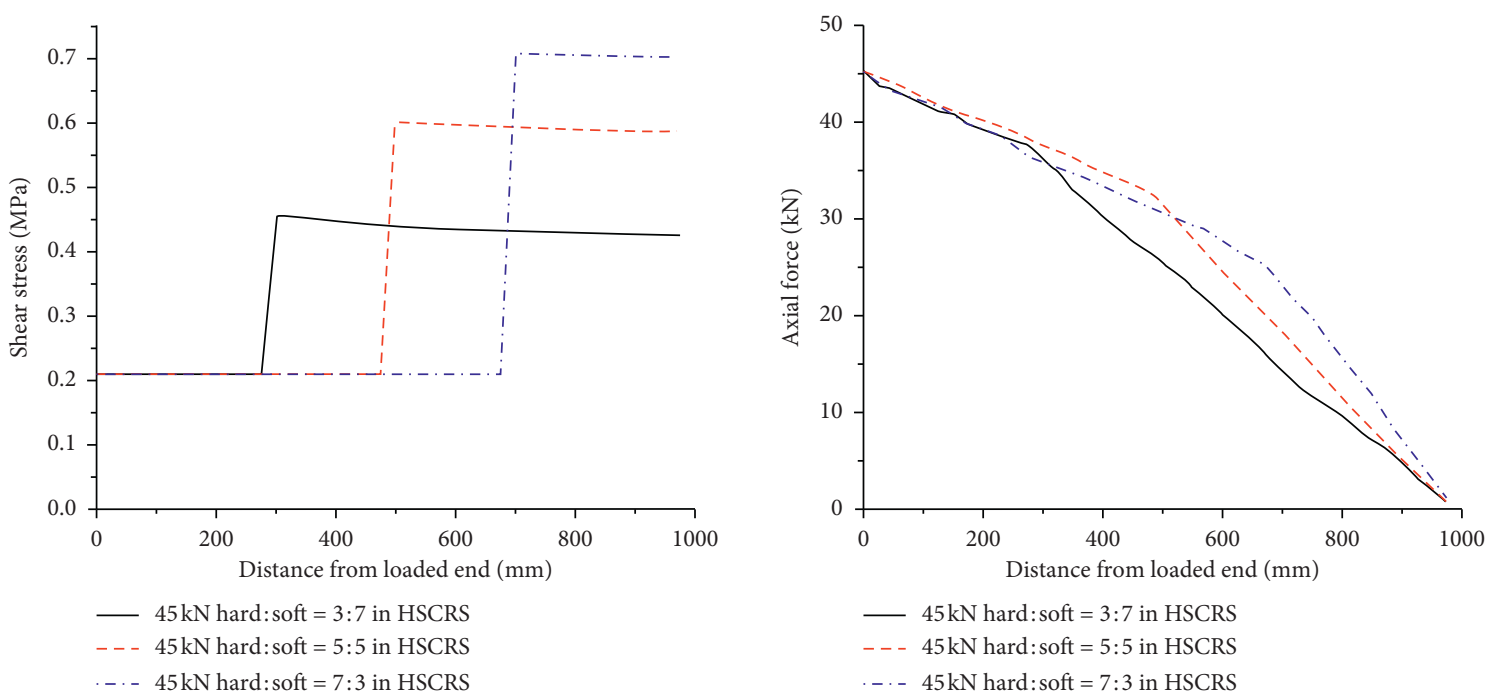

(c)

FIGURE 17: Shear stress (left) and axial force (right) distribution curves of soft to hard thickness ratios $(7: 3,5: 5$, and $3: 7)$ in HSCRS. (a) Linear stage. (b) Nonlinear stage. (c) Softening and debonding stage. 


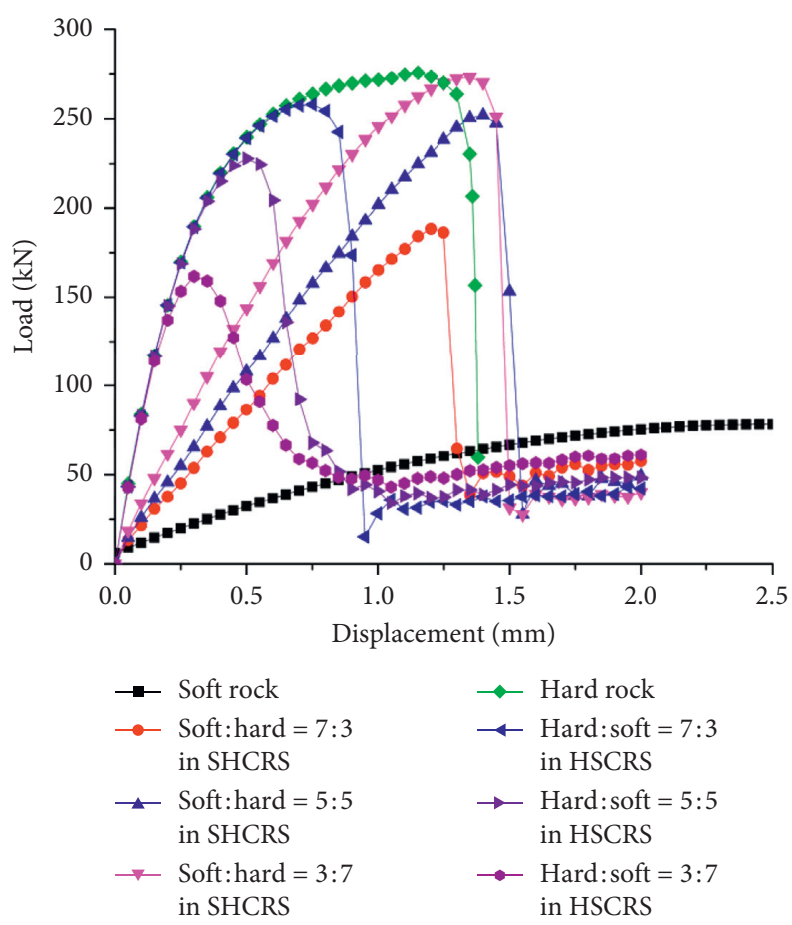

FIGURE 18: Load-displacement comparison curves under different soft and hard composite rock strata.

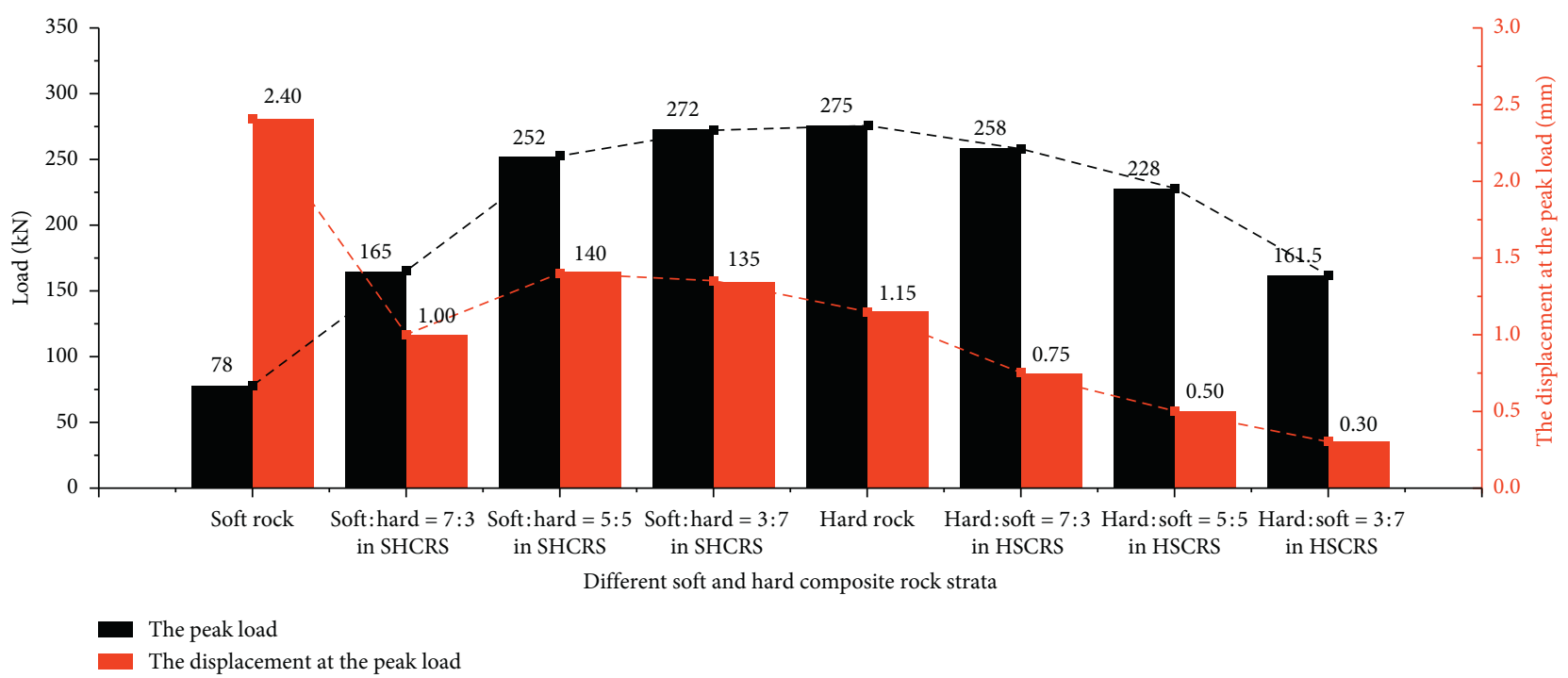

FIGURE 19: The peak load and the displacement at the peak load comparison under different soft and hard composite rock strata.

to the deep hard rock segment due to the increase of the hard rock thickness, the axial force curves attenuation gradient increases, and the bearing capacity of the anchoring system increases.

Softening and debonding stage: when the pulling load is $45 \mathrm{kN}$, the hard rock segment has been completely decoupled, the shear stress becomes a constant, and the axial force attenuates linearly, indicating that only the frictional resistance exists at the bond interface. The anchoring interface in soft rock is also in the elastic stage. Therefore, the shear stress curve and the axial force curve of the soft rock segment attenuate monotonically along the rock bolt. As the hard-to-soft thickness ratio increases, the peak shear stress increases and the peak axial force decreases of soft rock segment.

\subsection{Comparative Analysis of Load-Displacement Comparison} Curves under Different Soft and Hard Composite Rock Strata. The load-displacement curve is the macromechanical response of the mechanical properties of the anchoring system. The anchoring system has different pull-out responses due to the differences in the mechanical properties of soft rock and hard rock. This section analyzes the influence of lithological 


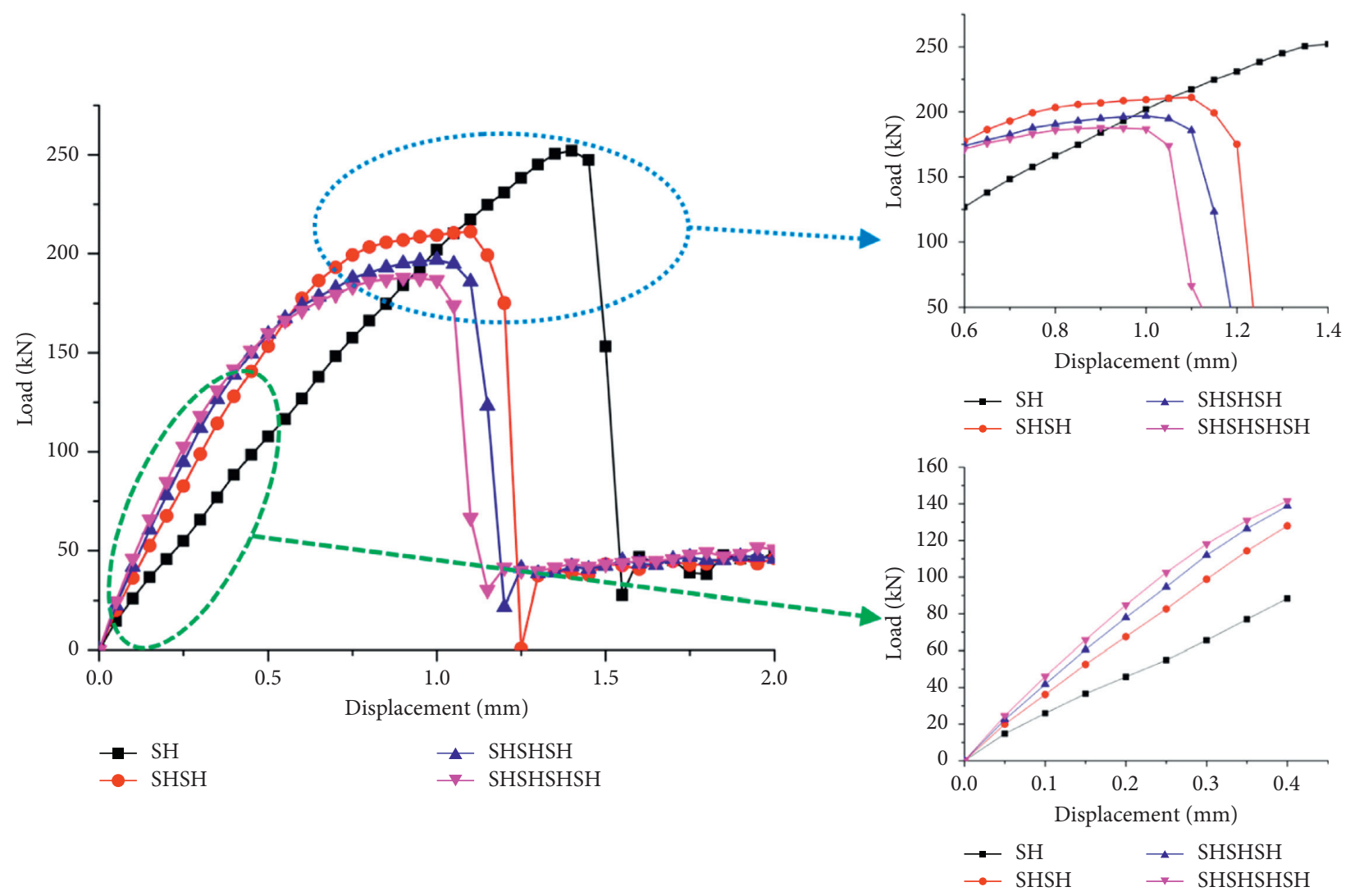

FIgURE 20: Influences of the layer number on the load-displacement responses.

sequences and layer thickness ratio on the load-displacement curves of the anchoring system.

Figure 18 shows the load-displacement comparison curves under different soft and hard composite rock strata. Figure 19 shows the peak load and the displacement at the peak load comparison under different soft and hard composite rock strata. It can be seen from Figures 18 and 19 that the peak load $(275 \mathrm{kN})$ of hard rock is 3.53 times that of soft rock $(78 \mathrm{kN})$; the displacement at the peak load $(2.4 \mathrm{~mm})$ of soft rock is 2.09 times that of hard rock $(1.15 \mathrm{~mm})$. Therefore, under the same anchor length, the bearing capacity of anchoring system in hard rock is obviously better than that in soft rock, but soft rock has a better ability to resist deformation.

As for the SHCRS, as the soft-to-hard thickness ratio decreases, the initial stiffness of the load-displacement curve increases, the peak load increases but the increasing magnitude decreases gradually, and the displacement at the peak load increases firstly and then decreases. It can be seen from Figure 19 that the peak load of soft-to-hard thickness ratio (7: $3,5: 5,3: 7$ ) in the SHCRS is increased by $111.54 \%, 223.08 \%$, and $248.72 \%$, respectively, compared with that in soft rock. Because the shallow soft rock segment bears the load firstly and the bond strength of soft rock is weak, the load is mainly borne by hard rock segment. With the increase of the hard rock thickness, bearing capacity of anchoring system gradually increases, but increasing magnitude decreases, indicating that there is a limit anchorage length.

As for the HSCRS, the hard rock segment bears the load firstly and the load-displacement curves show almost the same initial stiffness, but with the decrease of the hard rock thickness, the peak load and the peak displacement at the peak load decrease. It can be seen from Figure 19 that the peak load of hard-to-soft thickness ratio $(7: 3,5: 5$, and $3: 7)$ is decreased by $6.18 \%, 17.09 \%$, and $41.27 \%$, respectively, and the displacement at the peak load is decreased by $34.78 \%$, $56.52 \%$, and $73.91 \%$, respectively, compared with that in hard rock. The results show that the increase of the hard rock thickness in the HSCRS has little effect on the load-displacement curve under low load in the early stage of pulling out. As the pulling load increases, the bond interface will enter the softening and debonding stage and the peak shear stress transfers to the deep gradually. However, the interfacial shear stress in deep soft rock segment is small due to small relative slip. Once the hard rock segment is debonding, the soft rock segment is difficult to bear higher load. The load will decrease to a low level with a short displacement. Therefore, the effective anchoring length is only in the shallow hard rock segment for the HSCRS, and the anchoring length of the deep soft rock segment has little effect on the anchoring effect, which is equivalent to reducing the length of the anchoring segment. The engineering support design should ensure that the anchor end is located in a stable hard rock layer to ensure a good anchoring effect.

5.4. Layer Numbers. The influences of the distribution pattern of the layer number are discussed in this section. The SHCRS is taken as an example. The anchorage length 
of the rock bolt is $1 \mathrm{~m}$, which is divided into two layers, four layers, six layers, and eight layers, and the accumulated total thickness of the soft or hard rock layers is $0.5 \mathrm{~m}$. The typical load-displacement curves are shown in Figure 20. With the increase of the layer numbers, the hard rock is closer to the loading end, which leads to greater initial stiffness of the curve and lesser nonlinear section of the load-displacement curve. The result shows that the peak load decreases with the increase of the layer numbers, but the reduction magnitude decreases. When the layer number is two, the peak load is $252 \mathrm{kN}$, and the corresponding displacement is $1.4 \mathrm{~mm}$. When the layer number is four, the peak load is $211 \mathrm{kN}$, which is decreased by $16.3 \%$, and the corresponding displacement is $1.1 \mathrm{~mm}$, which is decreased by $21.4 \%$; when the layer number is six, the peak load is $196.8 \mathrm{kN}$, which is decreased by $21.9 \%$, and the corresponding displacement is $1 \mathrm{~mm}$, which is decreased by $28.6 \%$. When the layer number is eight, the peak load is $187 \mathrm{kN}$, which is decreased by $25.8 \%$, and the corresponding peak displacement is $0.9 \mathrm{~mm}$, which is decreased by $35.7 \%$. Therefore, the support system with thin layers and the multilayers surrounding rock will be more dangerous than that of the homogeneous rock masses.

\section{Conclusion}

In this paper, the bond-slip relationship of bond interface is obtained from the pull-out experimental data in homogeneous soft rock and hard rock, respectively. The bond-slip relationship is inputted into the numerical model by FISH. The influence of lithological sequence, layer thickness ratio, and layer numbers on mechanical properties of the anchoring system is obtained through a large number of simulation tests. Based on the analysis of the results, the conclusions are as follows.

(1) Under the same anchorage length, the bond strength of hard rock is obviously better than that of soft rock, but the anchoring system in soft rock has better deformation resistance. The hard rock segment bears mainly the external load in soft and hard composite rock strata. Different interfacial bond strength in soft rock and hard rock leads to both the shear stress curves and the axial force curves showing abrupt change at the soft-hard or hard-soft interface.

(2) Under the same layer number, the lithological sequences and layer thickness ratio are the key factors affecting the bearing capacity of the anchoring system. The anchoring system in SHCRS has a higher bearing capacity and deformation resistance than that in HSCRS. As for the SHCRS, the shallow soft rock segment bears the part load and mainly improves the deformation resistance. As for the HSCRS, the effective anchoring length is only in the shallow hard rock section, and the anchoring length of the deep soft rock segment has little effect on the bearing capacity of the anchoring system, which is equivalent to reducing the length of the anchoring segment. Therefore, the engineering support design should ensure that the anchor end is located in a stable hard rock stratum as much as possible to ensure a good anchoring effect.

(3) With the increase of the soft-to-hard thickness ratio in SHCRS, the initial stiffness of the load-displacement curve and the peak load decreases continuously. The closer the hard rock is to the loading end, the greater the initial stiffness of the load-displacement curve. The load-displacement curve shows the same initial stiffness for different hard to soft thickness ratio in HSCRS. As hard-to-soft thickness ratio increases in HSCRS, the peak load and the peak displacement at the peak load increase. The greater the hard rock thickness, the larger the peak load.

(4) Under the same anchor length, the peak load decreases as the layer numbers increase, but the reduction magnitude decreases. As the layer numbers increase, the hard rock is much closer to the loading end, resulting in larger initial stiffness and lesser nonlinear section of the load-displacement curve. Therefore, the anchoring system with thin layers and the multilayers surrounding rock will be more dangerous than that of the homogeneous rock masses.

\section{Data Availability}

The data used to support the findings of this study are included within the article.

\section{Conflicts of Interest}

The authors declare that they have no conflicts of interest.

\section{Acknowledgments}

The authors would like to acknowledge the financial support provided by the National Natural Science Foundation of China (nos. 51674250 and 51804302), Major Program of National Natural Science Foundation of China (no. 51734009), China Postdoctoral Science Foundation (no. 2019M652018), and National Key Research and Development Projects of China (no. 2019YFC1904304). The authors sincerely acknowledge the former researchers for their excellent works, which greatly assisted our academic study.

\section{References}

[1] D. Li, H. Masoumi, S. Saydam, and P. C. Hagan, "Mechanical characterisation of modified cable bolts under axial loading: an extensive parametric study," Rock Mechanics and Rock Engineering, vol. 51, no. 9, pp. 2895-2910, 2018.

[2] N. Hagan, P. Craig, A. Mirzaghorbanali et al., "Factors influencing the quality of encapsulation in rock bolting," Rock Mechanics \& Rock Engineering, vol. 49, no. 8, pp. 1-15, 2016.

[3] Y. Cai, T. Esaki, and Y. Jiang, "A rock bolt and rock mass interaction model," International Journal of Rock Mechanics and Mining Sciences, vol. 41, no. 7, pp. 1055-1067, 2004. 
[4] Y. Cai, T. Esaki, and Y. Jiang, "An analytical model to predict axial load in grouted rock bolt for soft rock tunnelling," Tunnelling and Underground Space Technology, vol. 19, no. 6, pp. 607-618, 2004.

[5] Y. Cai, Y. Jiang, I. Djamaluddin, and T. Esaki, "An analytical model considering interaction behavior of grouted rock bolts for convergence-confinement method in tunneling design," International Journal of Rock Mechanics and Mining Sciences, vol. 76, pp. 112-126, 2015.

[6] A. Iura and H. Soroush, "A theoretical approach for analysis of the interaction between grouted rockbolts and rock masses," Tunnelling and Underground Space Technology, vol. 20, no. 4, pp. 333-343, 2005.

[7] G. Xing, C. Zhou, T. Wu, and B. Liu, "Experimental study on bond behavior between plain reinforcing bars and concrete," Advances in Materials Science and Engineering, vol. 2015, Article ID 604280, 9 pages, 2015.

[8] S. Liu and P. K. Kaiser, "Bond strength of grouted cable bolts," International Journal of Rock Mechanics and Mining Sciences \& Geomechanics Abstracts, vol. 29, no. 3, pp. 279-292, 1992.

[9] A. J. Hyett, W. F. Bawden, and R. D. Reichert, "The effect of rock mass confinement on the bond strength of fully grouted cable bolts," International Journal of Rock Mechanics and Mining Sciences \& Geomechanics Abstracts, vol. 29, no. 5, pp. 503-524, 1992.

[10] A. J. Hyett, W. F. Bawden, and G. R. Macsporran, "A constitutive law for bond failure of fully-grouted cable bolts using a modified hoek cell," International Journal of Rock Mechanics and Mining Sciences \& Geomechanics Abstracts, vol. 32, no. 1, pp. 11-36, 1995.

[11] A. J. Moosavi, M. Moosavi, and W. F. Bawden, "Load distribution along fully grouted bolts, with emphasis on cable bolt reinforcement," International Journal for Numerical and Analytical Methods in Geomechanics, vol. 20, no. 7, pp. 517544, 1996.

[12] M. Moosavi, "A comprehensive comparison between bond failure mechanism in rock bolts and cable bolts," in Proceedings of the 9th ISRM Congress, pp. 1463-1466, Paris, France, August 1999.

[13] M. Moosavi, Load Distribution Laong Fully Goruted Cable Bolts Based on Constituitive Models Obtained from Modified Hoek Cells, Queen's University, Kingston, Canada, 1997.

[14] M. Moosavi, W. F. Bawden, and A. J. Hyett, "Mechanism of bond failure and load distribution along fully grouted cablebolts," Mining Technology, vol. 111, no. 1, pp. 1-12, 2002.

[15] A. Kilıc, E. Yasar, and A. G. Celik, "Effect of grout properties on the pull-out load capacity of fully grouted rock bolt," Tunnelling \& Underground Space Technology Incorporating Trenchless Technology Research, vol. 17, no. 4, pp. 355-362, 2002.

[16] I. Thenevin, L. Blanco-Martín, F. Hadj-Hassen, J. Schleifer, Z. Lubosik, and A. Wrana, "Laboratory pull-out tests on fully grouted rock bolts and cable bolts: results and lessons learned," Journal of Rock Mechanics and Geotechnical Engineering, vol. 9, no. 5, pp. 843-855, 2017.

[17] J. Chen, P. C. Hagan, and S. Saydam, "Sample diameter effect on bonding capacity of fully grouted cable bolts," Tunnelling and Underground Space Technology, vol. 68, pp. 238-243, 2017.

[18] B. Amadei, W. Z. Savage, and H. S. Swolfs, "Gravitational stresses in anisotropic rock masses," International Journal of Rock Mechanics \& Mining Sciences \& Geomechanics Abstracts, vol. 24, no. 1, pp. 5-14, 1992.
[19] M. T. Yong, C. K. Ming, and C. H. Juang, “An experimental investigation of the failure mechanism of simulated transversely isotropic rocks," International Journal of Rock Mechanics \& Mining Sciences, vol. 43, no. 8, pp. 1163-1181, 2006.

[20] D.-P. Xu, X.-T. Feng, D.-F. Chen, C.-Q. Zhang, and Q.-X. Fan, "Constitutive representation and damage degree index for the layered rock mass excavation response in underground openings," Tunnelling and Underground Space Technology, vol. 64, pp. 133-145, 2017.

[21] Y. Wang, B. Wu, Y. Guo, and H. Yang, "Numerical research on the pullout failure of GFRP bolt," Advances in Materials Science and Engineering, vol. 2017, Article ID 3025804, 11 pages, 2017.

[22] M. Salcher and R. Bertuzzi, "Results of pull tests of rock bolts and cable bolts in Sydney sandstone and shale," Tunnelling and Underground Space Technology, vol. 74, pp. 60-70, 2018.

[23] A. Teymen and A. Kilıç, "Effect of grout strength on the stress distribution (tensile) of fully-grouted rockbolts," Tunnelling and Underground Space Technology, vol. 77, pp. 280-287, 2018.

[24] I. W. Farmer, "Stress distribution along a resin grouted rock anchor," International Journal of Rock Mechanics and Mining Sciences \& Geomechanics Abstracts, vol. 12, no. 11, pp. 347351, 1975.

[25] O. Aydan, Y. Ichikawa, and T. Kawamoto, "Load bearing capacity and stress distributions in/along rockbolts with inelastic behavior of interfaces," in Proceedings of the Fifth International Conference on Numerical Methods in Geomechanics, Nagoya, Japan, April 1985.

[26] Ö. Aydan, Y. Ichikawa, and T. Kawamoto, "Reinforcement of geotechnical engineering structures by grouted rockbolts," in Proceedings of the International Symposium on Engineering in Complex Rock Formations, pp. 732-738, Beijing, China, November 1986.

[27] C. Li and B. Stillborg, "Analytical models for rock bolts," International Journal of Rock Mechanics and Mining Sciences, vol. 36, no. 8, pp. 1013-1029, 1999.

[28] B. Benmokrane, A. Chennouf, and H. S. Mitri, "Laboratory evaluation of cement-based grouts and grouted rock anchors," International Journal of Rock Mechanics and Mining Sciences \& Geomechanics Abstracts, vol. 32, no. 7, pp. 633-642, 1995.

[29] F. F. Ren, Z. J. Yang, J. F. Chen, and W. W. Chen, "An analytical analysis of the full-range behaviour of grouted rockbolts based on a tri-linear bond-slip model," Construction and Building Materials, vol. 24, no. 3, pp. 361-370, 2010.

[30] J. Dai, T. Ueda, and Y. Sato, "Development of the nonlinear bond stress-slip model of fiber reinforced plastics sheetconcrete interfaces with a simple method," Journal of Composites for Construction, vol. 9, no. 1, pp. 52-62, 2005.

[31] J. Dai, T. Ueda, and Y. Sato, "Unified analytical approaches for determining shear bond characteristics of FRP-concrete interfaces through pullout tests," Journal of Advanced Concrete Technology, vol. 4, no. 1, pp. 133-145, 2006.

[32] Y.-W. Zhou, Y.-F. Wu, and Y. Yun, "Analytical modeling of the bond-slip relationship at FRP-concrete interfaces for adhesively-bonded joints," Composites Part B: Engineering, vol. 41, no. 6, pp. 423-433, 2010.

[33] S. Ma, J. Nemcik, and N. Aziz, "An analytical model of fully grouted rock bolts subjected to tensile load," Construction and Building Materials, vol. 49, pp. 519-526, 2013.

[34] B. Martín, L. T. Michel, and Hadj-Hassen, "A new analytical solution to the mechanical behaviour of fully grouted rockbolts subjected to pull-out tests," Construction and Building Materials, vol. 25, no. 2, pp. 749-755, 2011. 
[35] L. B. Martin, F. Hadj-Hassen, M. Tijani et al., "A new experimental and analytical study of fully grouted rockbolts," in Proceedings of the 45th US Rock Mechanics/Geomechanics Symposium, American Rock Mechanics Association, San Francisco, CA, USA, pp. 11-16, June 2011.

[36] S. Ma, X. Zhu, W. Qin et al., "Determination of the bond-slip relationship of fully grouted rockbolts," Environmental Earth Sciences, vol. 77, no. 9, pp. 1-12, 2018.

[37] N. Vlachopoulos, D. Cruz, and B. Forbes, "Utilizing a novel fiber optic technology to capture the axial responses of fully grouted rock bolts," Journal of Rock Mechanics and Geotechnical Engineering, vol. 10, no. 2, pp. 222-235, 2018.

[38] Itasca Consulting Group, Fast Language Analysis of Continue in 3 Dimensions, Version 5.0, User's Manual, Itasca Consulting Group, Inc., Minneapolis, MN, USA, 2012.

[39] J. Nemcik, S. Ma, N. Aziz, and X. Geng, "Numerical modelling of failure propagation in fully grouted rock bolts subjected to tensile load," International Journal of Rock Mechanics and Mining Sciences, vol. 71, pp. 293-300, 2014.

[40] G. Rong, H. Zhu, and C. Zhou, "Testing study on working mechanism of fully grouted bolts of thread steel and smooth steel," Chinese Journal of Rock Mechanics and Engineering, vol. 23, no. 3, pp. 469-475, 2004.

[41] W. Chen and F. Ren, Mechanical Behavior of the Bamboo-Steel Composite Rockbolt, Lanzhou University, Lanzhou, China, 2008. 